IZA DP No. 4378

Grazing, Goods and Girth: Determinants and Effects

Daniel Hamermesh

August 2009 


\title{
Grazing, Goods and Girth: Determinants and Effects
}

\author{
Daniel Hamermesh \\ University of Texas at Austin, \\ NBER and IZA
}

\section{Discussion Paper No. 4378 \\ August 2009}

\author{
IZA \\ P.O. Box 7240 \\ 53072 Bonn \\ Germany \\ Phone: +49-228-3894-0 \\ Fax: +49-228-3894-180 \\ E-mail: iza@iza.org
}

\begin{abstract}
Any opinions expressed here are those of the author(s) and not those of IZA. Research published in this series may include views on policy, but the institute itself takes no institutional policy positions.

The Institute for the Study of Labor (IZA) in Bonn is a local and virtual international research center and a place of communication between science, politics and business. IZA is an independent nonprofit organization supported by Deutsche Post Foundation. The center is associated with the University of Bonn and offers a stimulating research environment through its international network, workshops and conferences, data service, project support, research visits and doctoral program. IZA engages in (i) original and internationally competitive research in all fields of labor economics, (ii) development of policy concepts, and (iii) dissemination of research results and concepts to the interested public.
\end{abstract}

IZA Discussion Papers often represent preliminary work and are circulated to encourage discussion. Citation of such a paper should account for its provisional character. A revised version may be available directly from the author. 
IZA Discussion Paper No. 4378

August 2009

\section{ABSTRACT \\ Grazing, Goods and Girth: Determinants and Effects}

Using the 2006-07 American Time Use Survey and its Eating and Health Module, I show that over half of adult Americans report grazing (secondary eating/drinking) on a typical day, with grazing time almost equaling primary eating/drinking time. An economic model predicts that higher wage rates (price of time) will lead to substitution of grazing for primary eating/drinking, especially by raising the number of grazing incidents relative to meals. This prediction is confirmed in these data. Eating meals more frequently is associated with lower $\mathrm{BMI}$ and better self-reported health, as is grazing more frequently. Food purchases are positively related to time spent eating - substitution of goods for time is difficult - but are lower when eating time is spread over more meals.

JEL Classification: J10

Keywords: time use, BMI, household production

Corresponding author:

Daniel Hamermesh

Department of Economics

University of Texas

Austin, TX 78712

USA

E-mail: hamermes@eco.utexas.edu 


\section{Introduction}

The reputed problem of obesity has been in the press increasingly in the past 20 years; and economists have poured substantial amounts of ink over the problem (as evidenced by the summaries and discussion in Cutler et al, 2003, and, Philipson and Posner, 2008, and the comparisons of the U.S. and Europe in Brunello et al, 2008). While numerous studies have examined the demographic correlates of obesity, using cross-section (e.g., Barnes, 2008) and even short longitudinal data (e.g., Halliday and Kwak, 2008), no study using representative data has examined obesity in the context of a production-function approach that includes what one would think are the major inputs into producing weight - time spent eating and purchased or home-produced food. The reason for this absence is clear: No representative data have existed that might have allowed such an analysis.

In this study I take a newly-created nationally representative data set and generate a model of eating that allows me to answer several questions related to obesity and health. The focus throughout is on the production of "eating" generally, with a particular focus on the distinction between primary eating/drinking (which I henceforth usually abbreviate as "eating") and eating/drinking while engaged in another activity that one views as primary (henceforth "grazing"). Examples of grazing are munching on a muffin while drafting an economics paper on one's computer, eating popcorn while watching television, and quaffing a beer while mowing the lawn. In these examples the primary activities are market work, leisure and home production respectively, and along with each primary activity grazing is occurring. In each case the individual can be viewed as engaged in "multi-tasking." 
I answer four specific questions: 1) How much eating and grazing goes on in the U.S., and what is its structure in terms of its division across a typical day? 2) What does an economic model predict about the determinants of eating and grazing, and what are the empirical determinants, both economic and demographic, of these activities? 3) How do eating and grazing affect weight, and how do they affect health? 4) How do eating and grazing time interact with purchased food, and how do these interactions affect weight and health? The general economic question throughout is how the value of time and time use affect the process of eating and its impacts on health outcomes. The result is a glimpse into how the timing and amount of eating are partly determined by economic considerations and thus how those choices about time spent eating and when and how to eat affect our health. The next section of this study discusses the data that I use and summarizes the new evidence on the average amounts of eating and grazing time. Section III presents a theory of grazing, while the subsequent three sections answer each of the last three questions outlined above.

\section{Data—and Some Evidence on Eating and Grazing}

In 2003 the U.S. Bureau of Labor Statistics initiated the American Time Use Survey (ATUS), based on the Current Population Survey (CPS), which provides the only set of time diaries anywhere in the world that is collected on a regular and frequent basis. ${ }^{1}$ These data have the virtue that subsets of the observations can be linked to the various CPS Supplements. In 2006 and 2007 each ATUS respondent was also asked to answer a set of additional questions and to fill out a supplemental diary that specifically inquired about his/her eating and drinking activities while engaged in other activities. With this Eating and Health Module, the 2006 and 2007 ATUS thus contains information

${ }^{1}$ See Hamermesh et al (2005) for a description of the features of these data. 
on what students of time diaries refer to as primary eating/drinking, and on secondary eating/drinking - what I refer to as grazing. Moreover, information on grazing is acquired with a timing dimension—we know when each episode starts and finishes—-thus allowing the computation of both the total amounts of eating and grazing and their temporal distributions. This dimension of the data allows us to consider eating and grazing in terms of their multiplicative components - their duration and incidence. That distinction is the same one that has proven fruitful in analyzing a variety of aspects of labor-market activity, such as unemployment, Adams (1985), labor-force participation, Hyslop (1999), and workplace injuries, Hamermesh and Wolfe (1990).

The ATUS provides 12,943 observations in 2006 and 12,248 in 2007. Some of each year's ATUS observations can be linked to the relevant December Food Security Supplement to the CPS, which provides information on weekly spending on food/drink for entire CPS households. From the 2006 (2007) ATUS we can match 2,970 $(2,730)$ individuals to the December 2005 (2006) Food Security Module.

Define total time spent in eating as:

$$
\mathrm{T}^{\mathrm{P}} \equiv \mathrm{t}^{\mathrm{P}} \mathrm{n}^{\mathrm{P}}
$$

and total time spent in grazing as:

$$
\mathrm{T}^{\mathrm{S}} \equiv \mathrm{t}^{\mathrm{S}} \mathrm{n}^{\mathrm{S}}
$$

where $t$ is the average duration of a spell of the activity, $n$ is the number of spells (the incidence of the activity), and the $\mathrm{P}$ and $\mathrm{S}$ denote eating and grazing activities. Figures $1 \mathrm{a}$ and $1 \mathrm{~b}$ graph the distributions of the $\mathrm{T}^{\mathrm{i}}, \mathrm{i}=\mathrm{P}, \mathrm{S}$. Figure $1 \mathrm{a}$ excludes the 4 percent of respondents who listed $\mathrm{T}^{\mathrm{P}}=0$ and the 0.3 percent who listed at least 400 minutes per day (all done for expositional convenience in the figure), so that the Figure is based on 24,058 
respondents. Figure $1 \mathrm{~b}$ excludes the 11,533 respondents who listed no grazing and the 1,315 respondents who grazed at least 400 minutes, so that the Figure is based on 12,343 respondents.

The first thing to note from the figures is that, conditional upon any grazing occurring, its distribution is much more dispersed, and much more skewed, than that of eating. Most people do not graze or graze very little, but a few are grazing for a large fraction of the day. Regarding the conditional means (based on all respondents with positive eating, or with positive grazing), $\mathrm{E}\left(\mathrm{T}^{\mathrm{P}} \mid \mathrm{T}^{\mathrm{P}}>0\right)=77.4$, while $\mathrm{E}\left(\mathrm{T}^{\mathrm{S}} \mid \mathrm{T}^{\mathrm{S}}>0\right)=$ 128.3, with unconditional means of 74.1 and $69.3 .^{2}$ Thus the average person is spending 2-1/2 hours per day eating/drinking, either primarily or secondarily, over $1 / 7$ of his/her waking hours.

Because a small number of respondents report that they are grazing during almost all of their waking hours, and because the relationships between eating and other activities, and drinking and other activities, may differ, Figure 1c presents information on secondary eating and eating/drinking, excluding time spent in secondary drinking that occurs without simultaneous eating. It excludes the 232 people who claimed to be engaged in secondary eating for at least 400 minutes and the 11,865 who reported no secondary eating, so that the Figure represents the activities of 13,094 respondents. The degree of skewness is much less than for total grazing, and the conditional mean is lower, $\mathrm{E}\left(\mathrm{T}^{\mathrm{SFOOD}} \mid \mathrm{T}^{\mathrm{SFOOD}}>0\right)=39.1$, with an unconditional mean of $20.7 .^{3}$

\footnotetext{
${ }^{2}$ All the statistics and estimates presented in this study weight the observations by the Eating and Health Module final weights.

${ }^{3}$ The ATUS classification system does not allow separating eating from drinking as main activities.
} 
Figures $2 \mathrm{a}$ and $2 \mathrm{~b}$ present the distributions of $\mathrm{n}^{\mathrm{P}}$ and $\mathrm{n}^{\mathrm{S}}$, conditional on positive values of the relevant $\mathrm{T}^{\mathrm{i}}$, while Figure $2 \mathrm{c}$ does the same thing but excludes periods of secondary drinking. ${ }^{4}$ As with the distributions of the $T^{\mathrm{i}}$, the distributions of $\mathrm{n}^{\mathrm{P}}$ and $\mathrm{n}^{\mathrm{SFOOD}}$ exhibit much less dispersion or skewness than the distribution of $\mathrm{n}^{\mathrm{S}}$. The means of $\mathrm{n}^{\mathrm{P}}, \mathrm{n}^{\mathrm{S}}$ and $\mathrm{n}^{\mathrm{SFOOD}}$, conditional on positive responses, are 2.02, 1.77 and 1.34 respectively. The unconditional means are $1.92,0.96$ and 0.71 respectively: The average respondent says s/he is eating almost exactly three times per day, although one of these is a period of grazing. Of the spells of grazing, $3 / 4$ involve some eating activity.

It is also interesting to note where grazing takes place, and what people are doing while grazing. Of all the minutes in $\mathrm{T}^{\mathrm{S}}$, almost exactly half occur during activities that are classified as leisure; and almost exactly half (not entirely the same half) take place at home. The same divisions between leisure and all other activities, and home and all other locations, exist for secondary eating alone. Thus half of what we are discussing is eating or drinking that complements leisure time and that occurs in close proximity to one's kitchen.

\section{A Theory of Grazing}

The purpose here is to outline a model that would allow predicting the impacts of changes in prices, particularly that of time, on the crucial variables $\mathrm{t}^{\mathrm{P}}, \mathrm{n}^{\mathrm{P}}, \mathrm{t}^{\mathrm{S}}$ and $\mathrm{n}^{\mathrm{S}}$. Obviously, part of the determinants of these duration and incidence measures depends on unobservable heterogeneity in preferences. Part too depends on the technology of eating/drinking: As the example of escargots might illustrate, it is difficult to eat some

\footnotetext{
${ }^{4}$ These figures exclude one person who listed more than six periods of primary eating/drinking, 24 who listed more than six periods of grazing, and one who listed more than six periods of secondary eating. These people are included in the statistical analyses, but given their scant numbers their inclusion had minimal effects on the results.
} 
foods while engaged in other activities — some foods are not suited for grazing, while others are (clearly endogenously) exquisitely suited for providing an accompaniment to some primary non-eating activity, typically a leisure-time activity. Also, eating often has a social aspect—conversation with friends and family is one reason why not all eating is secondary to other activities - the conversation is secondary. Here I ignore these issues, which essentially deal with technology, assume that all consumers face the same technology, and concentrate instead on the role of economic factors in affecting these outcomes.

Assume that the typical consumer seeks to maximize:

$$
\mathrm{U}=\mathrm{U}(\mathrm{Z}, \mathrm{F})-\mathrm{WS}\left(\mathrm{n}^{\mathrm{P}}\right),
$$

where $\mathrm{Z}$ is a composite commodity consisting of all non-food/drink items, F is the commodity food/drink, W is the individual's wage rate, and $S^{\prime}>0$. The only non-standard part of (2) is the final term: I assume that primary eating/drinking engenders set-up costs (see Gronau and Hamermesh, 2008), so that each incident of primary eating/drinking generates fixed costs that effectively reduce the time available for other things. This is not true for grazing. This distinction makes sense; indeed, foods designed for grazing presumably have arisen precisely because they do not engender set-up costs, or at least smaller set-up costs than those typically eat at mealtimes.

The consumer produces $\mathrm{Z}$ and $\mathrm{F}$ in the household using the technologies:

$$
\mathrm{Z}=\mathrm{Z}\left(\mathrm{X}^{\mathrm{Z}}, \mathrm{T}^{\mathrm{Z}}\left(\mathrm{T}^{\mathrm{S}}\right)\right), \mathrm{Z}_{\mathrm{i}}>0 ; \mathrm{Z}_{\mathrm{ii}}<0 ; \mathrm{T}^{\mathrm{Z}}{ }_{1}<0
$$

and:

$$
\mathrm{F}=\mathrm{F}\left(\mathrm{X}^{\mathrm{F}}, \mathrm{T}^{\mathrm{P}}, \mathrm{n}^{\mathrm{P}}, \mathrm{T}^{\mathrm{S}}\right), \mathrm{F}_{\mathrm{i}}>0, \mathrm{~F}_{\mathrm{ii}}<0,
$$


where the $\mathrm{X}$ are purchased goods inputs into home production. The crucial assumption here is the specification of $\mathrm{T}^{\mathrm{Z}}$ in (3a) as a decreasing function of $\mathrm{T}^{\mathrm{S}}$. The more an individual grazes, the lower is the productivity of his/her time in the primary activity that the grazing accompanies. Grazing is not a free good-my eating a muffin while trying to write a paper to some extent reduces my efficiency in getting my ideas together and onto the page in a coherent form. (The specification of $n^{P}$ in (3b) is necessary to ensure that the consumer could maximize at $\mathrm{n}^{\mathrm{P}}>1$-could possibly consume more than one meal a day.) The individual faces the standard Becker (1965) goods and time constraints:

$$
\begin{aligned}
& \text { (4a) } \mathrm{WT}^{\mathrm{H}}+\mathrm{I}=\mathrm{p}_{\mathrm{X}} \mathrm{X}^{\mathrm{Z}}+\mathrm{p}_{\mathrm{F}} \mathrm{X}^{\mathrm{F}} \text {; } \\
& \text { (4b) } \mathrm{T}^{\mathrm{H}}+\mathrm{T}^{\mathrm{Z}}+\mathrm{T}^{\mathrm{P}}=24
\end{aligned}
$$

where $\mathrm{T}^{\mathrm{H}}$ is daily hours of market work, and $\mathrm{I}$ is unearned income per day.

As is standard in household production models, working time is the residual, determined by choices about the other endogenous variables, in this case: $\mathrm{X}^{\mathrm{Z}}, \mathrm{X}^{\mathrm{F}}, \mathrm{T}^{\mathrm{Z}}, \mathrm{T}^{\mathrm{S}}$, $\mathrm{t}^{\mathrm{P}}$ and $\mathrm{n}^{\mathrm{P}}$. As I have specified the maximization problem and the technology of household production, $\mathrm{t}^{\mathrm{S}}$ and $\mathrm{n}^{\mathrm{S}}$ are not treated separately. Nonetheless, because $\mathrm{n}^{\mathrm{P}}$ enters the maximand separately from $\mathrm{t}^{\mathrm{P}}$, we can draw some inferences about the effects of the forcing variables, $\mathrm{W}$ and $\mathrm{I}$, on the duration/incidence mix of eating. ${ }^{5}$ The power of the model comes from the assumptions that only eating has set-up costs each time it is undertaken, while grazing reduces the efficiency of time spent in producing the other (non-eating) commodity.

\footnotetext{
${ }^{5}$ We could specify $\mathrm{T}^{\mathrm{P}}$ and $\mathrm{T}^{\mathrm{S}}$ in $(3 \mathrm{~b})$ even more generally as functions of the $\mathrm{t}^{\mathrm{i}}$ and $\mathrm{n}^{\mathrm{i}}$, but, since we know nothing about the nature of this aspect of producing $\mathrm{F}$, this generalization would not add to our ability to predict the impacts of changing $\mathrm{W}$ and $\mathrm{I}$.
} 
The consumer solves for these six outcomes. Note first that, as is standard in household production models, increases in I produce a pure income effect, shifting all production to greater goods intensity; and part of the impact of an increase in W is also a pure income effect, which also produces the same rise in goods intensity. The question I focus on is only that of how changes in these variables alter the optimizing outcomes $\mathrm{T}^{\mathrm{S}^{*}}$, $\mathrm{t}^{\mathrm{P} *}$ and $\mathrm{n}^{\mathrm{P} *}$. We cannot sign the effects of an increase in $\mathrm{I}^{6}{ }^{6}$ An increase in $\mathrm{W}$, however, while it may increase or decrease the total amount of time devoted to the production of $\mathrm{Z}^{\mathrm{F}}$, will, by raising the set-up costs of primary eating/drinking, cause a shift within $\mathrm{T}^{\mathrm{P}}$ toward $\mathrm{t}^{\mathrm{P}}$ and away from $\mathrm{n}^{\mathrm{P}}$. We should thus expect the relative incidence of eating compared to grazing to fall, since the rise in $\mathrm{W}$ produces no clear effect on $\mathrm{n}^{\mathrm{S}}$.

Since I have assumed that duration and incidence are multiplicative in (3b), it may also be that $T^{P}$ falls relative to $T^{S}$. Regardless of the narrow specification of the household technology of producing the commodity eating/drinking, within this model a higher wage will be associated with more spells of grazing relative to spells of eating. Moreover, it is likely that a higher price of time will generate an increase in the amount of grazing relative to the amount of primary eating/drinking. If one were to expand the model to include both of the $\mathrm{T}^{\mathrm{i}}$ and $\mathrm{n}^{\mathrm{i}}$ separately in (3b), with sufficient restrictions one could, depending on the nature of substitution between $\mathrm{t}^{\mathrm{S}}$ and $\mathrm{n}^{\mathrm{S}}$, obtain predictions about the duration/incidence mix of grazing. I do not, however, think that we know enough to impose those restrictions.

\footnotetext{
${ }^{6}$ In any case, since we do not observe unearned income in our data, this inability is irrelevant for what is in the end an empirical exercise.
} 


\section{The Determinants of Grazing}

The simplest examination of the predictions in the model can be seen by comparing workers and non-workers. In this section I define workers as anyone who reports both positive usual weekly hours and positive usual weekly earnings; nonworkers are other respondents. Before examining the differences in eating time and incidence by labor-market status, it is worth noting from the right-hand panel of Table 1 that all the differences in labor-market status by demographic characteristic make sense: Workers are younger, more likely to be male, white or married, and more educated than non-workers.

The crucial comparisons are in the left-hand panel of Table 1. Workers spend significantly less time in eating than non-workers (remember, I denote primary eating/drinking by "eating" throughout), and the incidence of eating is also significantly lower among workers. This may be a confirmation of our theory, but it may simply result from an adding-up problem: Part of the representative day of the average worker is spent in market work, so that there are just fewer minutes available for all other activities, including eating.

More clear-cut confirmation of the model's predictions comes when we compare the patterns of $\mathrm{T}^{\mathrm{P}}$ and $\mathrm{T}^{\mathrm{S}}$, and $\mathrm{n}^{\mathrm{P}}$ and $\mathrm{n}^{\mathrm{S}}$, across the two groups. The amount of grazing is much greater among workers than among non-workers. This is especially so if we include secondary drinking, but even secondary eating alone is more prevalent among workers. Moreover, almost all of the difference in the averages of the $\mathrm{T}^{\mathrm{S}}$ across the two groups results from differences in the $\mathrm{n}^{\mathrm{S}}$ rather than the $\mathrm{t}^{\mathrm{S}}$. Overall, this simple list of means provides basic evidence in support of the predictions of the economic model. 
While the differences by labor-force status in the descriptive statistics presented in Table 1 are suggestive, only a formal test of the theory could be convincing. Before doing that, however, it is worthwhile examining the demographic correlates of the four outcomes, $T^{P}, T^{S}, n^{P}$ and $n^{S}$. Because of the small number of integer outcomes that we observe for the $\mathrm{n}^{\mathrm{i}}$, I generate the estimates of their determinants using Poisson regressions. Because nearly half the ATUS respondents report no grazing, the estimates of the determinants of $\mathrm{T}^{\mathrm{S}}$ are based on tobit estimation.

In Table 2 I present the effects of the demographic variables on the six outcomes. For a substantial number of demographic factors the effects on eating, both its total and its incidence, are opposite those on grazing. Thus there is a U-shaped pattern with age of eating; but the relationship of grazing and its incidence with age is inverse-U-shaped or continuously decreasing. Indeed, the trough in eating occurs at roughly the same age as the peak in grazing. The effect of gender is also opposite along these two dimensions: Men are more likely to report eating (and to engage in more incidents of it) but less likely to graze or eat secondarily (and they engage in fewer incidents of grazing). Being married, however, is positively correlated with more "regular" eating, but also with more grazing. Race too has the same correlations with eating and grazing (with non-Hispanic whites eating/drinking and grazing more than respondents of other races/ethnicities).

Moving up the education ladder, each extra level of educational attainment is associated with more total time spent eating, more incidents of eating, more total time spent grazing and more incidents of grazing (although the relationship is weaker for total time spent in secondary eating). People with post-graduate degrees engage in primary eating/drinking for 25 minutes more per day than high-school drop-outs (especially 
surprising since the latter have more non-market time available for eating), and do so more often per day. While not a direct test of the theory, it is worth noting that the gradient in educational attainment, which is positively correlated with the price of time, is steeper in $n^{S}$ than in $n^{P}$. Along this single dimension related to time price we see that, as predicted, the incidence of grazing rises relative to that of eating.

To test the hypothesis generated from the model in Section III formally, I restrict the sample to those individuals for whom I can calculate an hourly wage rate (usual weekly earnings divided by usual weekly hours). To avoid errors induced by division bias, the sample is further restricted to those respondents whose (derived) wage rate is at least the 2006-07 minimum wage of $\$ 5.15$ and no more than $\$ 100$ per hour. $^{7}$ The results of the estimation (again, with the appropriately different estimation methods for the several outcomes) are presented in Table 3. Each coefficient estimate shows the impact of the wage rate on the particular outcome. The estimates in Column (1) include the entire vector of control variables listed in Table 2; those in Column (2) exclude the vector of education indicators, while Column (3) excludes all controls.

The results strongly support the theory. In the complete model (Column (1)) the estimates imply that an increase in the wage rate leads to significantly more time spent eating (consistent with evidence in Hamermesh, 2008, of a low elasticity of substitution of goods for time in producing the commodity eating). Nonetheless, workers do not increase the incidence of eating as their wage rate increases. In other words, higher wages

\footnotetext{
${ }^{7} \mathrm{I}$ do not impute an hourly wage rate for those individuals for whom none is available (because they were out of the labor force). Given the evidence in Table 2 that the usual identifier of female labor-force participation, presence of children, partly determines eating time, it is unclear how one would identify the selection mechanism in this context. The extent of feedback from eating time or eating frequency to wage determination would seem minor, and that from grazing trivial, however, suggesting in any event that selection bias is unlikely to be a major issue here.
} 
lengthen the time spent per primary eating/drinking interval, as predicted. Total grazing also rises with wages, both through a significant increase in the number of times per day that the worker spends grazing and an increase in the duration per incident. The second implication of the model — that incidents of grazing will rise relative to incidents of eating/drinking - is strongly supported in the data, whether we focus on all grazing or exclude secondary drinking. All of the general conclusions are strengthened as we move to equations with fewer covariates. Even though Column (3) shows that all the wage terms are statistically significant, we still find that most of the rise in primary eating/drinking with the wage rate occurs through a lengthening of periods of eating; and we still observe the same relative increase in the incidence of grazing, either in total or in secondary eating alone, compared to that of primary eating/drinking. ${ }^{8}$

\section{The Effects of Eating and Grazing Time on Weight and Health}

As noted in Section II, the Eating and Health Module of the ATUS also collected interview data that enabled the construction of measures of BMI and subjective health status. The BMI measure is calculated from the respondent's reported weight and height. BMI clearly has problems as a measure of the impact of weight on health (see Burkhauser and Cawley, 2008; Johanssen et al, 2009); but it is the only such measure available in this, the only data set that provides information for a large sample on both eating time and weight. The subjective health status measure is the standard five-point Likert scale: Excellent, very good, good, fair and poor. While this measure too has difficulties (Lindeboom and van Dorslaer, 2004)), it is not clear for purposes of

\footnotetext{
${ }^{8}$ One might view hourly-paid workers as having less flexibility to graze while on the job. There are, however, no significant differences by hourly pay status in the amount of grazing, defined broadly or narrowly, that occurs in the workplace; but conditional on reporting any grazing, it is less likely to occur at work if the person is paid hourly.
} 
measuring the impacts of the correlates of health that its deficiencies are particularly severe (and see Hennessy et al, 1994, for evidence of its success in predicting mortality and morbidity).

\section{A. Descriptive Statistics}

Consider first the BMI measure. Figures $3 \mathrm{a}$ and $3 \mathrm{~b}$ respectively graph the BMI of the Eating and Health Module respondents for men and women (excluding the 5 men and 26 women whose calculated BMI lies outside the 15 to 55 range, on the assumption that those calculations result from gross over/underestimates of height and/or weight). The figures thus reflect the BMI of 10,552 men and 13,108 women (so that, as can be seen by a simple calculation, a BMI measure was not obtained from 1500 of the respondents). ${ }^{9}$

Also included in each graph is a kernel estimate of the density function of BMI.

Note first that both distributions are skewed to the right, as is standard in other data sets, with the density for women being more strongly skewed than that for men. 1.0 percent of men are underweight (BMI less than 18.5); 42.6 percent are overweight (BMI at least 25 and less than 30), and 27.1 percent are obese (BMI at least 30). The comparable figures for women are 2.4 percent, 28.9 percent and 25.0 percent.

The distributions of these series of reported BMI are shown in Columns (1) and (3) of Table 4 for respondents ages 20 or over. Cawley (2004), using the NLSY from 1981 through 2000, obtains an average BMI (based on self-reported weight and height) of

\footnotetext{
${ }^{9}$ Item non-response on the BMI measure is unfortunately not independent of the observables: An equation predicting non-response that includes all of the measures in Table 2 has a pseudo- $\mathrm{R}^{2}$ of 0.065 , with the most important determinant of non-response being gender (women are more likely not to report BMI data than men). BMI is only missing for 6 percent of the respondents, of whom 1 percentage point were pregnant women whose weight was not collected. Since the overwhelming majority of the variance in the probability of non-response is not accounted for by the observables, it is unlikely that item non-response is having an important effect on our estimates. Regardless, there is little that we can do empirically about this difficulty in this data set.
} 
25.8. Taking the same age, gender and racial/ethnic weights as in the NLSY data for those years, the ATUS data yield an average BMI of 26.9, substantially higher than in the NLSY, perhaps due to greater misreporting, or perhaps to an upward trend in true BMI. The NHANES data for 2003-2006 are shown in Columns (2) and (4) of the table. For men the distribution of BMI is strikingly similar to that in the ATUS data. Among women, however, the NHANES shows increasingly higher BMI as compared to the ATUS moving up the distributions. The differences suggest greater underreporting by women than men, especially if women's true BMI continued to trend up between 20032005 and 2006-07. They also imply the need to examine impacts on BMI at various quantiles of the distributions of BMI.

The distributions of the responses about subjective health are shown for men and women separately in Table 5. As is common with this measure, most people view their health as at least good, and the majority consider it at least very good. Moreover, the distributions are significantly different by gender, with fewer women than men viewing their health as excellent, and more viewing it as fair or poor. ${ }^{10}$

\section{B. Determinants of BMI}

While the focus is on the impacts of $\mathrm{T}^{\mathrm{P}}$ and $\mathrm{n}^{\mathrm{P}}$, and $\mathrm{T}^{\mathrm{S}}$ and $\mathrm{n}^{\mathrm{S}}$, a good check on the validity of the data comes from an examination of their partial correlations with wellknown demographic variables and standard economic measures. Thus in Column (1) of Table 6 I present the results of OLS estimates of an equation describing BMI that excludes the time-use measures. Most of the results accord with the substantial previous work on the relation between BMI and demographic characteristics. Thus men's BMI

\footnotetext{
${ }^{10}$ This difference by gender is standard even for other health measures in a variety of countries, as shown by Strauss et al (1993).
} 
exceeds women's, other things equal; there is an inverse-U-shaped relationship with age, with the peak at 54; and non-Hispanic whites' BMI is about 1 less than that of Hispanics and blacks. These demographic effects are quite similar to those found by Baum (2007) using the NHANES. There are only small differences in BMI by educational attainment among those who have not graduated from college; but college graduates' BMI is about 1.4 less than that of individuals with lower educational attainment, and people with postgraduate degrees have BMIs that are nearly 2 below those of individuals who did not graduate from college. The other two demographic factors, marital status and number of children, have little partial relation to BMI.

Overall the consistency of the demographic effects on BMI should enhance one's confidence in the reliability of the BMI data and thus in the impacts of time use on BMI on which I focus. ${ }^{11}$ Each of Columns (2)-(7) presents results for various combinations of the primary eating/drinking and grazing measures, and each also includes all the demographic variables from Column (1). Consider first the impacts of time spent in primary eating/drinking. As the estimate in Column (2) shows, spending more time eating reduces BMI, other things equal. A two standard-deviation increase in time spent eating, other things equal, lowers BMI by about $0.2 .^{12}$

When we break $\mathrm{T}^{\mathrm{P}}$ into its components by adding $\mathrm{n}^{\mathrm{P}}$ to the estimating equation, as in Column (3), it becomes clear that the negative effect of time spent eating on BMI arises almost entirely through the frequency of eating, not the duration per incident of

\footnotetext{
${ }^{11}$ Work using the Eating and Health Module relating BMI to time spent in various activities has recently been done by Pinkston and Stewart (2009).

${ }^{12}$ Nutritionists have considered the relationship between eating frequency (incidence in our terminology) and weight for smaller samples, focusing on how eating frequency is related to energy expenditure and weight (Barba et al, 2006; Duval et al, 2008).
} 
eating. The decrease in BMI with time spent at meals is due almost entirely to the impact of spreading the same amount of eating time over more meals. This result suggests that the hoary parental command, "Chew your food!", which presumably means eating more slowly, may be incorrect, since reducing the time spent at each meal (equivalent to eating more meals in the same total time) lowers BMI. At least the numerical part of the other adage, "Eat three square meals a day," is, however, supported by these results. ${ }^{13}$

When we expand the estimating equations to include $\mathrm{T}^{\mathrm{S}}$, as in Column (4), or both $\mathrm{T}^{\mathrm{S}}$ and $\mathrm{n}^{\mathrm{S}}$, as in Column (5), the implications about the effects of $\mathrm{T}^{\mathrm{P}}$ and $\mathrm{n}^{\mathrm{P}}$ from Columns (2) and (3) on BMI remain almost completely unchanged: The impact of eating on BMI remains negative and is due mostly to the negative effect of more frequent eating, conditional on total eating time. The same is true in Columns (6) and (7), where we define grazing narrowly to exclude time spent in drinking as a secondary activity.

Additional time spent grazing broadly defined has a negative, but insignificant effect on BMI; and the results in Column (5) suggest that decomposing $\mathrm{T}^{\mathrm{S}}$ into its two components does not alter this conclusion. Perhaps surprisingly, more grazing or more frequent grazing does not significantly affect BMI. These negative results may arise from the inclusion of long spells of (perhaps over-reported) secondary drinking in $\mathrm{T}^{\mathrm{S}}$. Narrowing the definition of grazing to exclude drinking, as in the final two columns, changes the conclusion about its impact: Additional grazing time functions exactly like additional primary eating/drinking time in lowering BMI; and much of the effect is due to spreading the same amount of time over more incidents.

While the estimates in Table 6 summarize the average effects of total eating time and the incidence of eating on BMI, the best measure of weight for height that we have in

\footnotetext{
${ }^{13}$ Replacing $\mathrm{n}^{\mathrm{P}}$ by an indicator for three meals per day yields a significant negative effect on BMI.
} 
this data set, they do not get at the possible impacts of eating and grazing at the main locus of policy concern, the upper part of the distribution of weight, and obesity in particular. Given some evidence for children (Barnes, 2008) that the impacts of the forcing variables of interest may differ along the distribution of BMI, in Table 7 I present a variety of estimates of the effects of the time-use variables at two points in the upper tail of that distribution, the $90^{\text {th }}$ and the $95^{\text {th }}$ percentiles of BMI. Each equation for which the coefficients on the time input measures are shown in Table 7 also includes the entire vector of demographic variables included in the equations in Table $6 .{ }^{14}$

At the upper extreme of the distribution of BMI the results are in the same direction as at the mean (and median) and are even roughly the same size. As at the mean of BMI, additional time spent grazing has no significant effects on BMI, here whether we define grazing broadly or narrowly as secondary eating only. The general conclusions from this table are that the effects of time use in eating on BMI do not vary greatly moving up the distribution of BMI from the mean.

\section{Determinants of Self-Reported Health}

The relationship between self-reported health and BMI is negative, with a pseudo$\mathrm{R}^{2}$ in the ordered probit of the health measure on BMI in this sample of 0.027 . Moreover, as the results in Column (1) of Table 8 show, the coefficients on the demographic variables are almost always the opposite sign of those in Column (1) of Table 6 (with the only exceptions being those of gender and the lower categories of educational attainment). Each additional level of educational attainment significantly increases the ordered probit index above its value at the next-lower level. These results are generally

\footnotetext{
${ }^{14}$ The estimates at the median of the distribution are qualitatively very similar to those from the OLS regressions summarized in Table 6, so to save space I do not present them here.
} 
consistent with what other studies of the effect of education on health have found (e.g., Strauss et al, 1993).

Columns (2)-(7) in Table 8 are constructed identically to their counterparts in Table 6, again including all the demographic covariates, and adding various combinations of the eating and grazing measures. The results for eating look very similar to those in Table 6. As with BMI, so too with self-reported general health, more time spent eating is associated with a more desirable outcome. Here, however, more time per incident of eating and additional incidents both have significant beneficial effects on self-reported health. Overall better health is associated with more time spent eating, but especially with spreading that time over more meals per day. ${ }^{15}$

The conclusions about the effects of time spent in primary eating/drinking and its components are unaffected by the addition (in Columns (4)-(7)) of measures of grazing. The components of grazing have mixed effects on self-reported health, with the impact of total time spent grazing depending on whether we define grazing broadly or narrowly. No matter what the definition is, however, more frequent grazing is significantly associated with better health status. Thus spreading one's eating time over more incidents has the same beneficial qualitative impact on this outcome as on BMI, whether these are meals or just snacks consumed while engaged in other activities. ${ }^{16}$

\footnotetext{
${ }^{15}$ Note that this is not explicable by differences in income, at least those attributable to the usual explanatory factors of age, education and demographics, as all of these are included as controls in these estimates.

${ }^{16} \mathrm{~A}$ number of doctors recommend frequent daily meals and snacks (consistent with limited caloric intake) to control weight, and a Dutch television personality, Sonja Bakker, has proselytized for this approach.
} 


\section{Making Fat: A Household Production Approach to BMI}

The general issue in this section is the interaction between purchased food and time spent eating and grazing, including the duration and incidence dimensions of time, and how these interactions affect weight and health. Hamermesh (2008) and Lim and Rodriguez (2008) are the only studies to examine the interaction between $\mathrm{X}^{\mathrm{F}}$ and $\mathrm{T}^{\mathrm{P}}$ formally for random samples of respondents (although Bertrand and Schanzenbach, 2009, looked at a small sample of older women, concentrating on time use and caloric intake in a non-formal examination). In this, to my knowledge the first study combining spending, meals and grazing, I do not follow their example because of the difficulty of incorporating the various dimensions of time spent on food (both eating and grazing, and each of their incidence and duration). Instead, I examine their correlations and how they affect outcomes.

As noted in Section II, the data are a small subset of those used above. From the linkage of the ATUS to the CPS December Food Security Supplements, I obtained for each respondent household the previous week's food spending and its usual weekly food spending. The difficulty is that food spending is by the entire household, while the timeuse information describes only one household member. While imputing time use for other household members is possible (see Hamermesh, 2007), to avoid concerns about its validity I begin the analysis here with one-person households-unmarried adults with no children. This generates a restricted sub-sample of only 2,262 individuals from the 200607 ATUS. To expand the sample I then use equivalence scales to deflate household food spending for married-couple households with zero, one or two children under age 18 (the 
overwhelming majority of married couples). ${ }^{17}$ Adding these to the single-person childless households I obtain an expanded sub-sample of 4,582 respondents.

\section{A. The Interaction of Goods and Time}

Table 9 presents the means of the food-time measures for the restricted and expanded sub-samples and the descriptive characteristics of the respondents' demographics. On the latter several unsurprising differences stand out in comparison to the overall sample (whose characteristics were presented in Table 1). The crucial differences arise from the fact that the restricted sub-sample is much older, and also more heavily female, than the entire sample, which results from the presence of substantial numbers of unmarried older women (many widows). Because of the age difference, the respondents are much less likely to be Hispanic or workers than members of the entire sample. The allocation of time to eating differs very little from the average of workers and non-workers displayed in Table 1, especially for the expanded sub-sample. Multiplying the food expenditure measures by 52 weeks, we note, especially for reported spending last week in the restricted sub-sample, that they are substantially higher than the annual average of $\$ 3,328$ by one-person households reported in the Consumer Expenditure Survey for $2007 .{ }^{18}$ The difference is smaller for usual weekly food spending; and comparing spending by the expanded sub-sample to what is implied by the CES, the excess of usual weekly spending in the CPS data is only 5 percent.

\footnotetext{
${ }^{17}$ The equivalence scale used is the OECD modified scale, which assigns weights of 1.5 to an adult couple with no children, 1.8 to a couple with one child, and 2.1 to a couple with two children.

${ }^{18} \mathrm{http}: / /$ www.bls.gov/cex/2007/Standard/cusize.pdf . Whether this difference is the result of an intercept shift, or instead reflects reporting errors correlated with the other characteristics, cannot be known without a proper validation study.
} 
The first step is to examine how people combine goods and time. In Table $10 \mathrm{I}$ present estimates that relate food purchases (previous week in Columns (1)-(4), usual week in Columns (5)-(8)) to eating time and the number of eating incidents. The central result is that total eating time is positively related to total food spending. This is not surprising - it takes time to eat the food that one has purchased. Implicitly, $F_{12}$ in (3b) is positive. Given the amount of time spent eating, however, breaking it up into more incidents is associated with a substantial reduction in food spending ( $F_{13}$ in (3b) is implicitly negative). Those people who eat more, but more hurried meals, combine that time with fewer purchased goods. The effect is not small: Going from two to three meals per day reduces last week's (usual weekly) food spending by between 3 and 6 percent in these sub-samples.

The odd-numbered columns include grazing defined broadly, while the evennumbered columns only include secondary eating as grazing. These estimates suggest that, while additional time spent grazing is associated with more food spending, there is generally no statistically significant relationship between the two (although the coefficients on the broad measure of grazing approach statistical significance). Perhaps this is because spending on grazing goods is a small fraction of total food spending.

\section{B. Joint Impacts on BMI and Health}

How do the inputs into the household production of eating affect BMI and health? Table 11 presents estimates of their impacts on BMI, with the first four columns using previous week's spending to represent $\mathrm{X}^{\mathrm{F}}$ and the second four based on usual weekly food spending. I present the estimates separately for the restricted and expanded subsamples. Because some of the respondents failed to provide health and/or BMI data, the 
sub-samples are reduced still further in size. The first thing to note is that the food spending terms have positive impacts on BMI that are statistically significant for last week's spending. Since Baum and Ruhm (2009) have shown that BMI does not rise with income over most of its range in the contemporary U.S., this finding is hard to rationalize for the superior good, food.

These regressions are just an extension of some of those presented in Table 6, with the addition of $\mathrm{X}^{\mathrm{F}}$ but limited to fewer than twenty percent of that sample's respondents. I therefore discuss the results on time inputs in comparison to their counterparts in Columns (5) and (7) of that table. Considering only the estimates for the restricted sub-sample (of childless single-person households), they look very different from the estimated effects presented in Table 6, especially in terms of the effects of total time and the incidence of primary eating/drinking. A comparison to the estimates for the expanded sub-sample shows, however, that the contrast is due to the unusual nature of the restricted sub-sample. For the expanded sub-sample, whose demographic characteristics approximate more closely those of a random sample of the adult population, the estimated impacts of eating time on BMI look very much like those shown in equations that do not include food spending. Additional time spent in eating has no effect on BMI, but spreading it out over more meals reduces BMI. Additional time spent grazing is associated with lower BMI, but, given the amount of grazing time, more incidents have no impact on BMI. A fair conclusion from the comparison of results across the two tables is that the impact on BMI of eating time and its distribution is independent of that of spending on food. 
In Table 12 I present estimates analogous to those presented in Table 11, but here they are ordered-probit parameters describing the determinants of subjective health. While the estimates for the restricted sub-sample look different from those for the entire sample in Table 8, those for the expanded sub-sample look fairly similar and merit no comment. What is novel here, however, is that additional food spending is associated with better subjective health. Since I have held constant a vector of variables that are the usual predictors of earnings and income, this result can be interpreted as arising independent of income effects on health-given income, more spending on food is related to better health. I do not claim that the relationship is causal-those who are in better health may choose to spend more on food, given their incomes; the only claim is that this is a partial correlation, independent of any relationship between subjective health and income.

Clearly, the second goal of this Section-successfully describing the determinants of BMI and health by a complete set of food inputs - cannot be achieved using the restricted sub-sample. If, however, we equivalence scales to apportion households' food spending to the individuals whose time diaries are collected by the ATUS, the exercise seems to be successful. From it we learn that additional food spending raises BMI and improves subjective health, although both effects are quite small.

\section{Conclusions, Completions and Implications}

Using the first available data set that links time use to weight and health outcomes, I have examined how time spent eating, both at and between meals, affects these objective and subjective outcomes. The focus, moreover, has been on both the amount of time eating and grazing and on their distributions across the day-in 
particular, the duration and incidence of eating time. The most interesting association is between the frequency of eating and weight and health outcomes - those who eat more meals, conditional on total eating time, weigh less and report better health than do their demographically identical counterparts. The distribution of time spent eating is an economic outcome: When time becomes more valuable (as proxied by the hourly wage), people substitute grazing for eating, essentially switching to multi-tasking an activity that may be one of the more readily multi-tasked.

There are a number of different substantive extensions to this study that one could undertake. A formal model of goods-time substitution could be estimated (to infer the elasticity of substitution between goods and time in the production of the commodity food); and that model could be expanded to allow for two kinds of time inputs-eating and grazing - and even for the duration and incidence components of each of these. Indeed, the same exercise could be undertaken more generally. For any commoditycombination of goods and time-we could with the appropriate data consider how both the duration and timing of the activity interact with goods purchases. There is no reason to assume that the duration and incidence of time use are separable from goods purchases in household production; and, since I have shown here that duration and incidence have different effects on important outcomes, examining differences in their substitutability for other kinds of purchased goods would be relevant for studying other outcomes as well.

More difficult would be serious formal modeling of the economic determinants of the impacts of eating and grazing time on weight and health. I have treated the determination of BMI in a static model, but it can be thought of more broadly as the outcome of dynamic maximization by a consumer acting under uncertainty about both 
resources and the impact of food spending and time use in the production of BMI. Given the statistical significance of some of the relationships here, particularly between the incidence of eating (meals) and BMI and health, it would be worthwhile using longitudinal data to examine how these are affected by the price of time through both income and substitution effects and how those change over the life cycle. 


\section{References}

James Adams, "Permanent Differences in Unemployment and Permanent Wage Differentials," Quarterly Journal of Economics, 100 (February 1985): 29-56.

G. Barba, E. Troiano, P. Russo and A. Siani, "Total Fat, Fat Distribution and Blood Pressure According to Eating Frequency in Children Living in Southern Italy: The ARCA Project," International Journal of Obesity, 30 (Feb. 2006): 1166-9.

Stephen Barnes, Three Essays in Health Economics. Unpublished Ph.D. Dissertation, University of Texas, 2008.

Charles Baum, "The Effects of Race, Ethnicity and Age on Obesity," Journal of Population Economics, 20 (2007): 687-705.

and Christopher Ruhm, "Age, Socioeconomic Status and Obesity Growth," Journal of Health Economics, 2009 forthcoming.

Gary Becker, “A Theory of the Allocation of Time," Economic Journal, 75 (Sept. 1965): 493-517.

Marianne Bertrand and Diane Schanzenbach, "Time Use and Food Consumption," American Economic Association, Papers and Proceedings, 99 (May 2009): 1706.

Giorgio Brunello, Pierre Michaud and Anna Sanz de Galdeano, "The Rise in Obesity across the Atlantic: An Economic Perspective," IZA Discussion Paper No. 3529, June 2008.

Richard Burkhauser and John Cawley, "Beyond BMI: The Value of More Accurate Measures of Fatness and Obesity in Social Science Research," Journal of Health Economics, 27 (March 2008): 519-29.

John Cawley, "The Impact of Obesity on Wages," Journal of Human Resources, 39 (Spring 2004): 451-74.

David Cutler, Edward Glaeser and Jesse Shapiro, "Why Have Americans Become More Obese?” Journal of Economic Perspectives, 17 (Summer 2003): 93-118.

Karine Duval, Irene Strychar, Marie-Josée Cyr, Denis Prud'homme, Rémi Rabasa-Lhoret and Éric Doucet, "Physical Activity is a Confounding Factor of the Relation between Eating Frequency and Body Composition," American Journal of Clinical Nutrition, 88 (Nov. 2008): 1200-5. 
Reuben Gronau and Daniel Hamermesh, "The Demand for Variety: A Household Production Perspective," Review of Economics and Statistics, 90 (Aug. 2008): $562-72$.

Timothy Halliday and Sally Kwak, "Weight Gain in Adolescents and their Peers," IZA Discussion Paper No. 3610, July 2008.

Daniel Hamermesh, "Time to Eat: Household Production under Increasing Income Inequality," American Journal of Agricultural Economics, 89 (Nov. 2007): 85263. (Jan. 2008): 31-4.

and John Wolfe, "Compensating Wage Differentials and the Duration of Wage Loss," Journal of Labor Economics, 8 (Jan. 1990): S175-97.

, Harley Frazis and Jay Stewart, "Data Watch: The American Time Use Survey,” Journal of Economic Perspectives, 19 (Winter 2005): 221-32.

Catherine Hennessy, David Moriarty, Matthew Zack, Paul Scherr and Robert Brackbill, "Measuring Health-Related Quality of Life for Public Health Surveillance," Public Health Reports, 109 (Sept.-Oct. 1994): 665-72.

Dean Hyslop, "State Dependence, Serial Correlation and Heterogeneity in Intertemporal Labor Force Participation of Married Women," Econometrica, 67 (Nov. 1999): 1255-94.

Edvard Johansson, Petri Böckerman, Urpo Kiiskinen and Markku Heliövaara, "Obesity and Labour Market Success in Finland: The Difference between Having a High BMI and Being Fat," Economics and Human Biology, 7 (March 2009): 36-45.

Jean Lim and Carolina Rodriguez Zamora, "The Optimal Tax Rule in the Presence of Time Use,” Unpublished paper, University of Texas at Austin, 2008.

Maarten Lindeboom and Eddy van Doorslaer, "Cut-Point Shift and Index Shift in SelfReported Health," Journal of Health Economics, 23 (Nov. 2004): 1083-99.

National Center for Health Statistics (NCHS), National Health Statistics Reports, Number 10, October 22, 2008.

Tomas Philipson and Richard Posner, "Is Obesity a Public Health Problem? A Decade of Research on the Economics of Obesity?" NBER Working Paper No. 14010, May 2008. 
Josh Pinkston and Jay Stewart, "How Does Time Use Affect the Probability of Becoming Obese?” Unpublished paper, Bureau of Labor Statistics, June 2009.

John Strauss, Paul Gertler, Omar Rahman and Kristin Fox, "Gender and Life-Cycle Differentials in the Patterns and Determinants of Adult Health," Journal of Human Resources, 28 (Fall 1993): 791-837. 


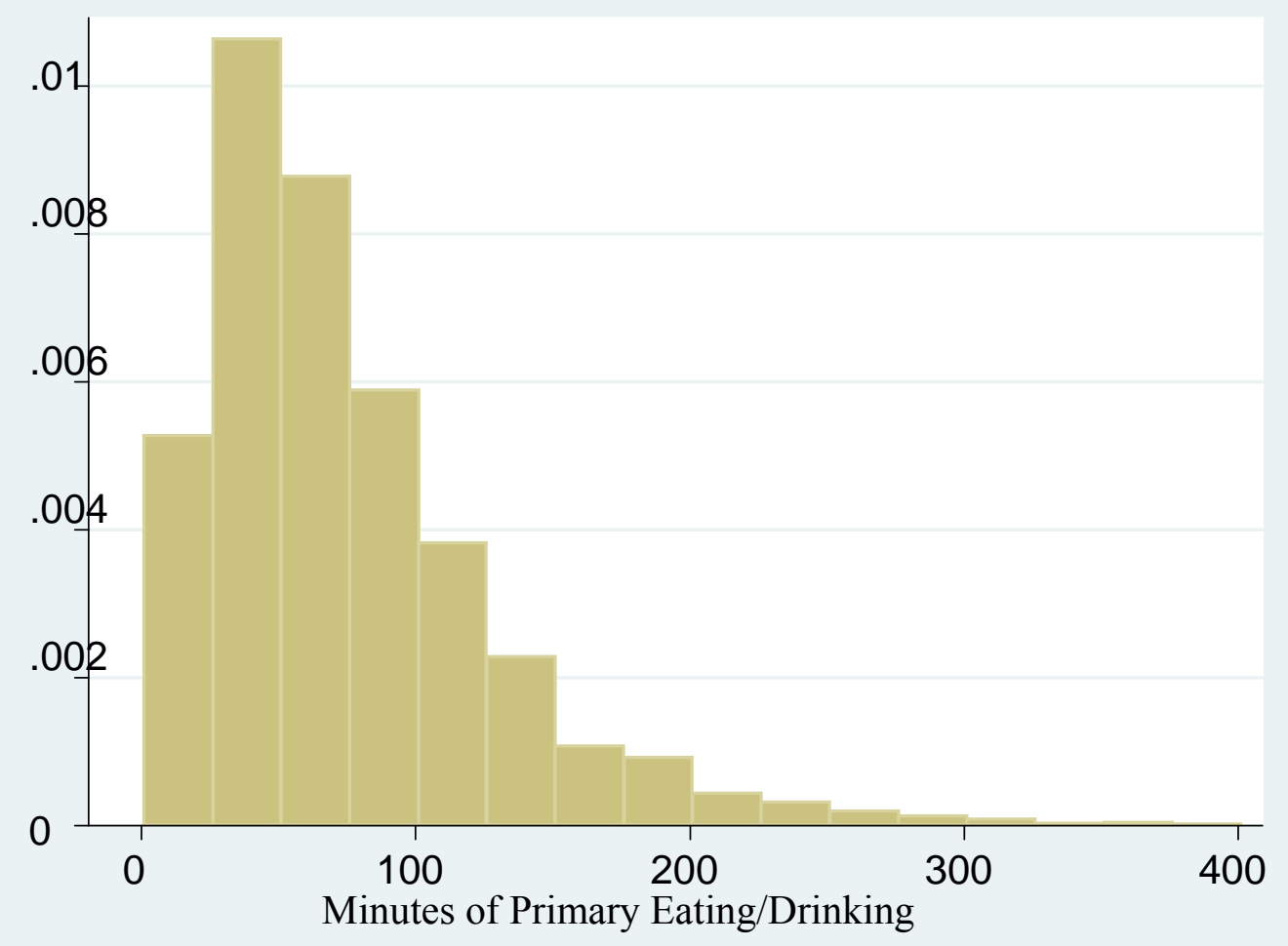

Figure 1a. Histogram of Primary Eating/Drinking Time, Time $>0$ and $<400$ Minutes/Day 


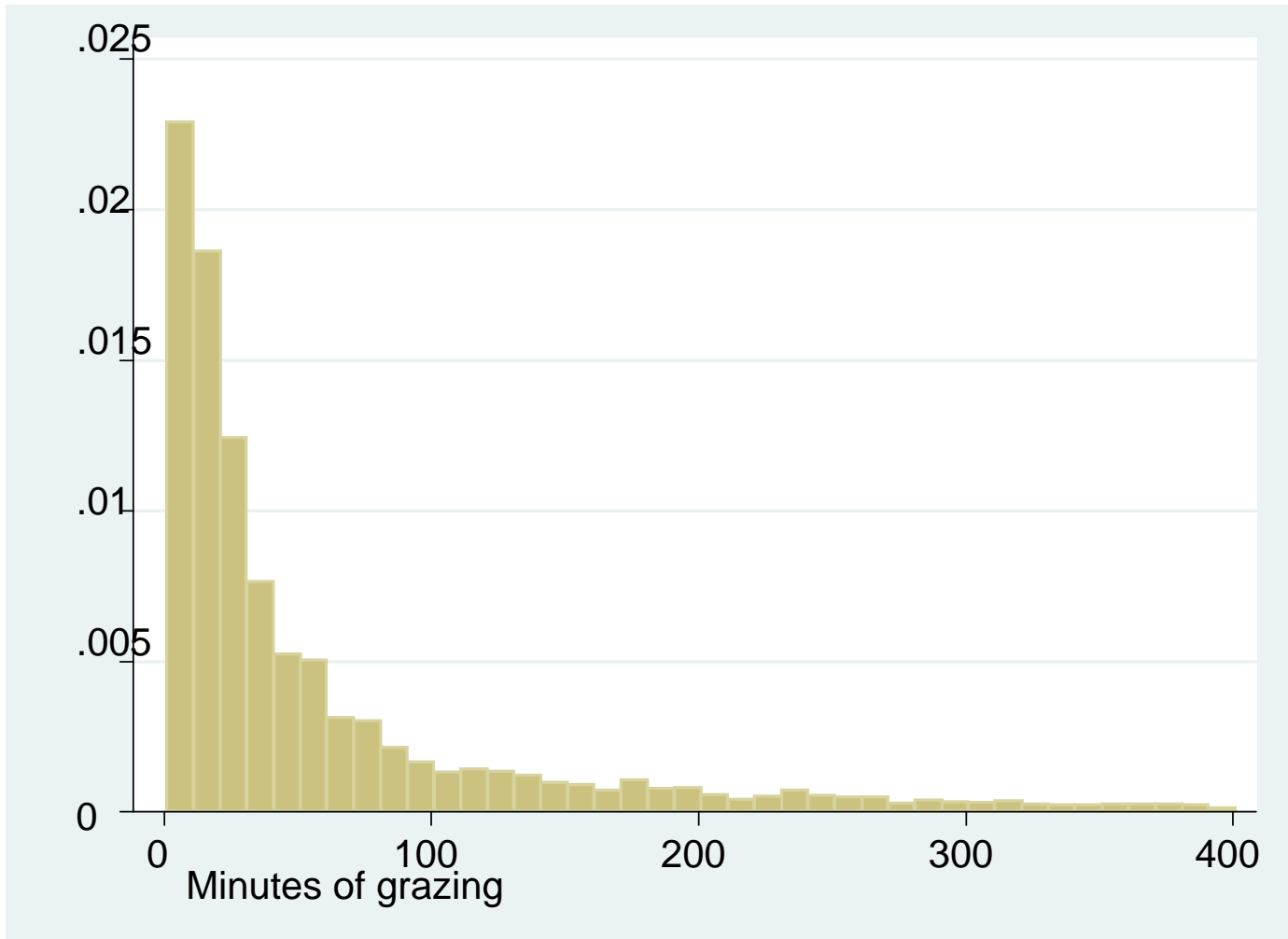

Figure 1b. Histogram of Grazing Time, Time $>0$ and $<400$ Minutes/Day 


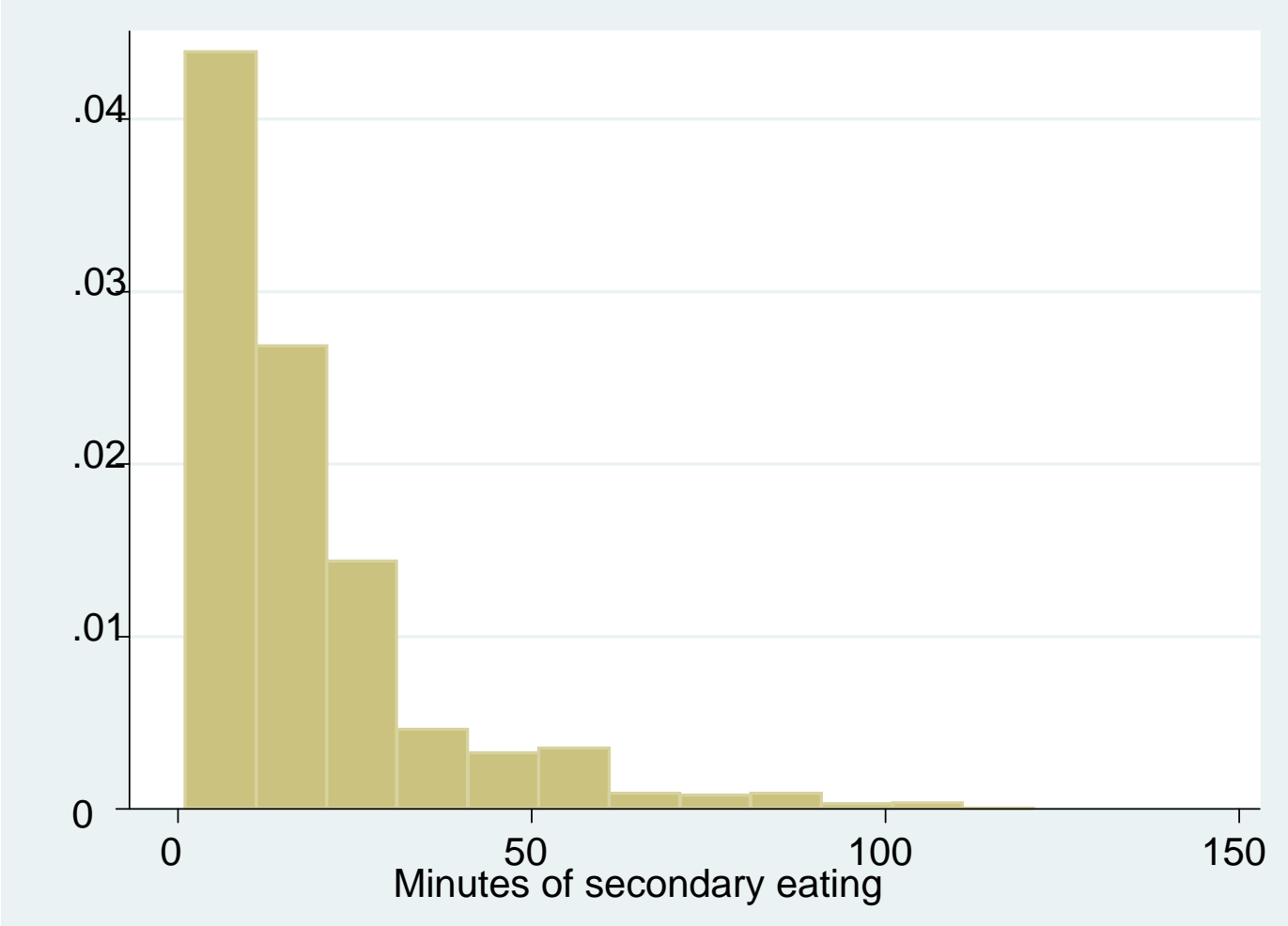

Figure 1c. Histogram of Secondary Eating Time, Time $>0$ and $<400$ Minutes/Day 


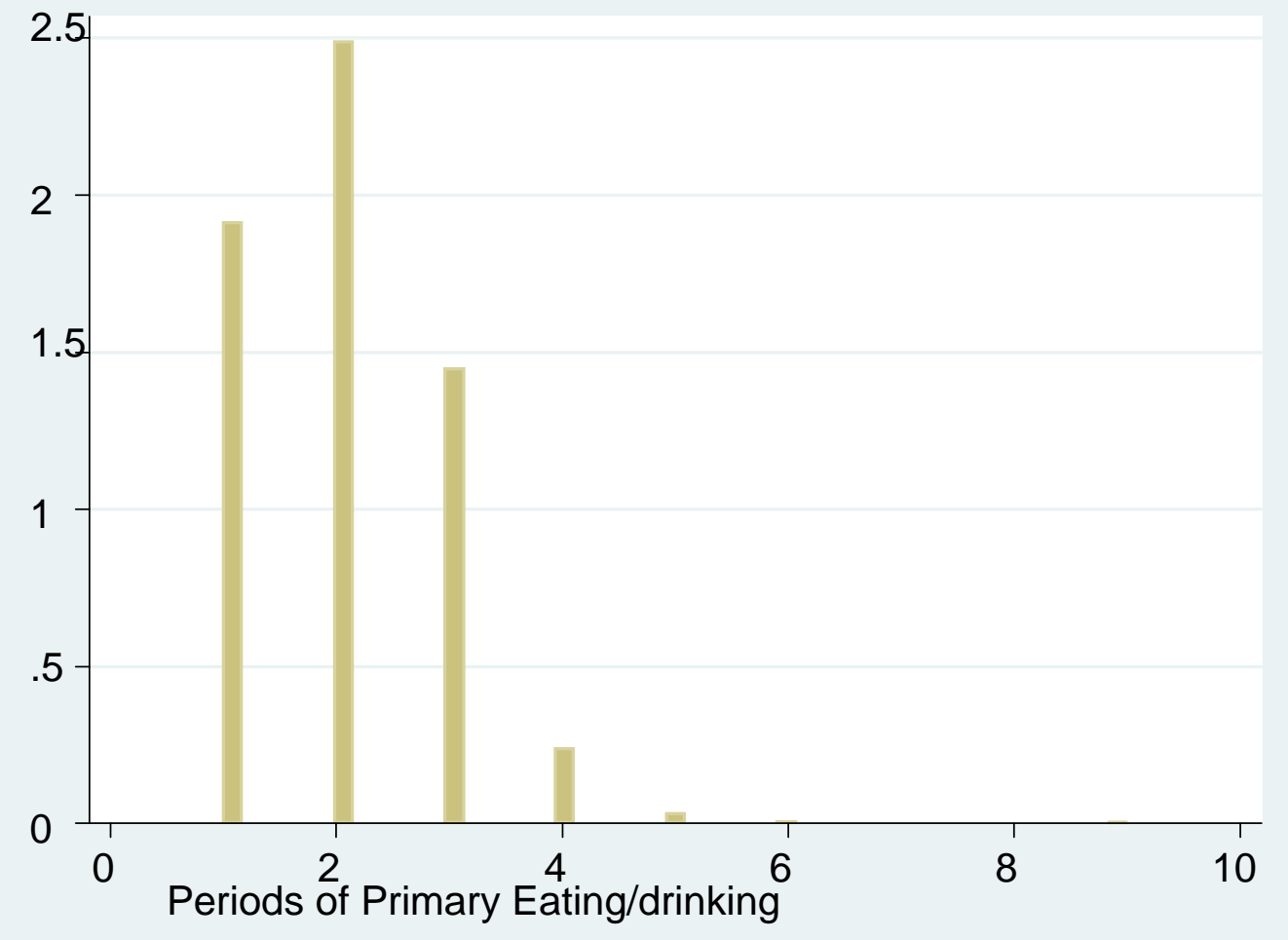

Figure 2a. Histogram of Intervals of Primary Eating/Drinking (Excluding the 4.0\% with no Primary Eating/Drinking) 


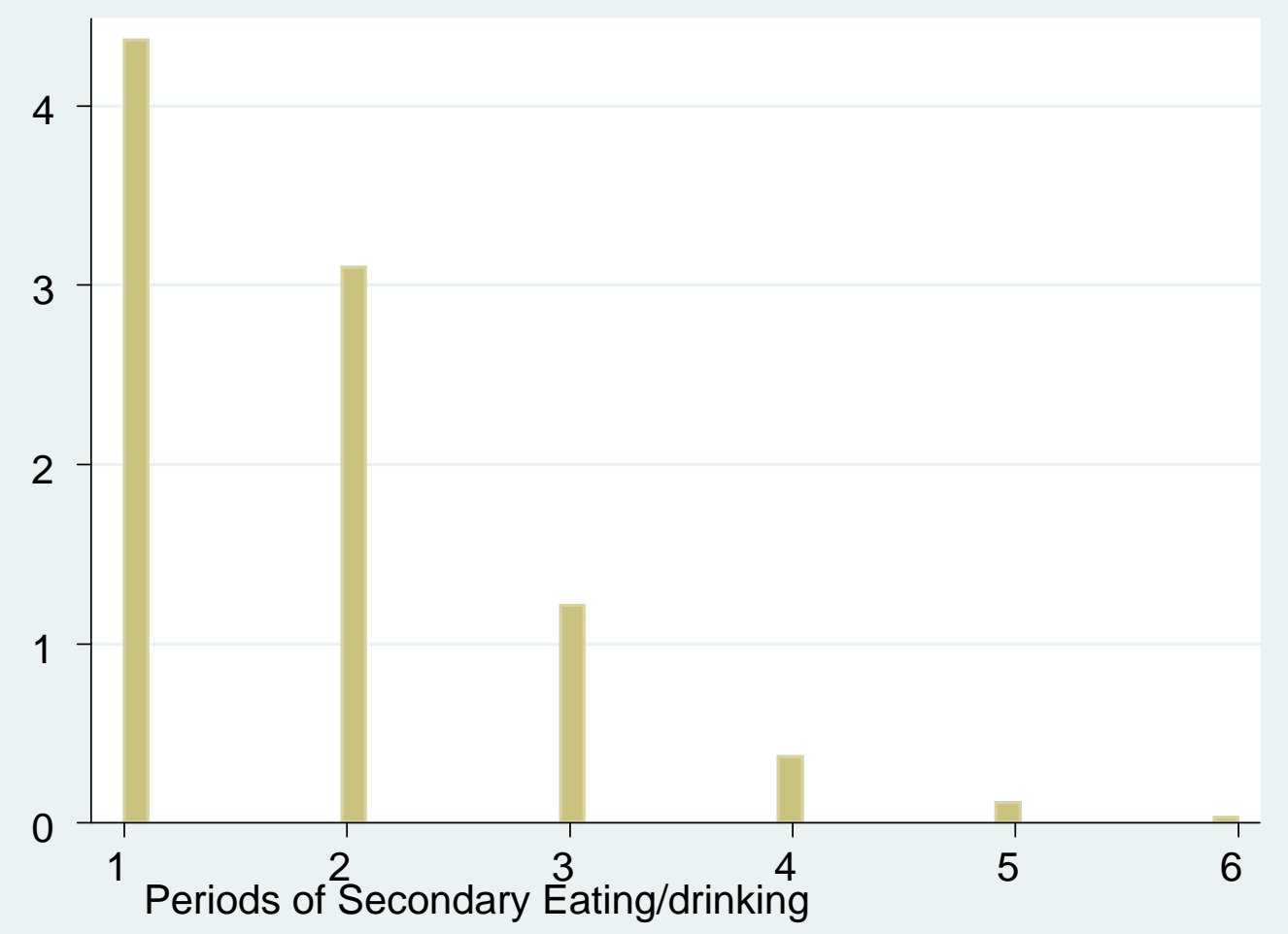

Figure 2b. Histogram of Intervals of Secondary Eating/Drinking (Excluding the 0.1\% with More than 6 Intervals) 


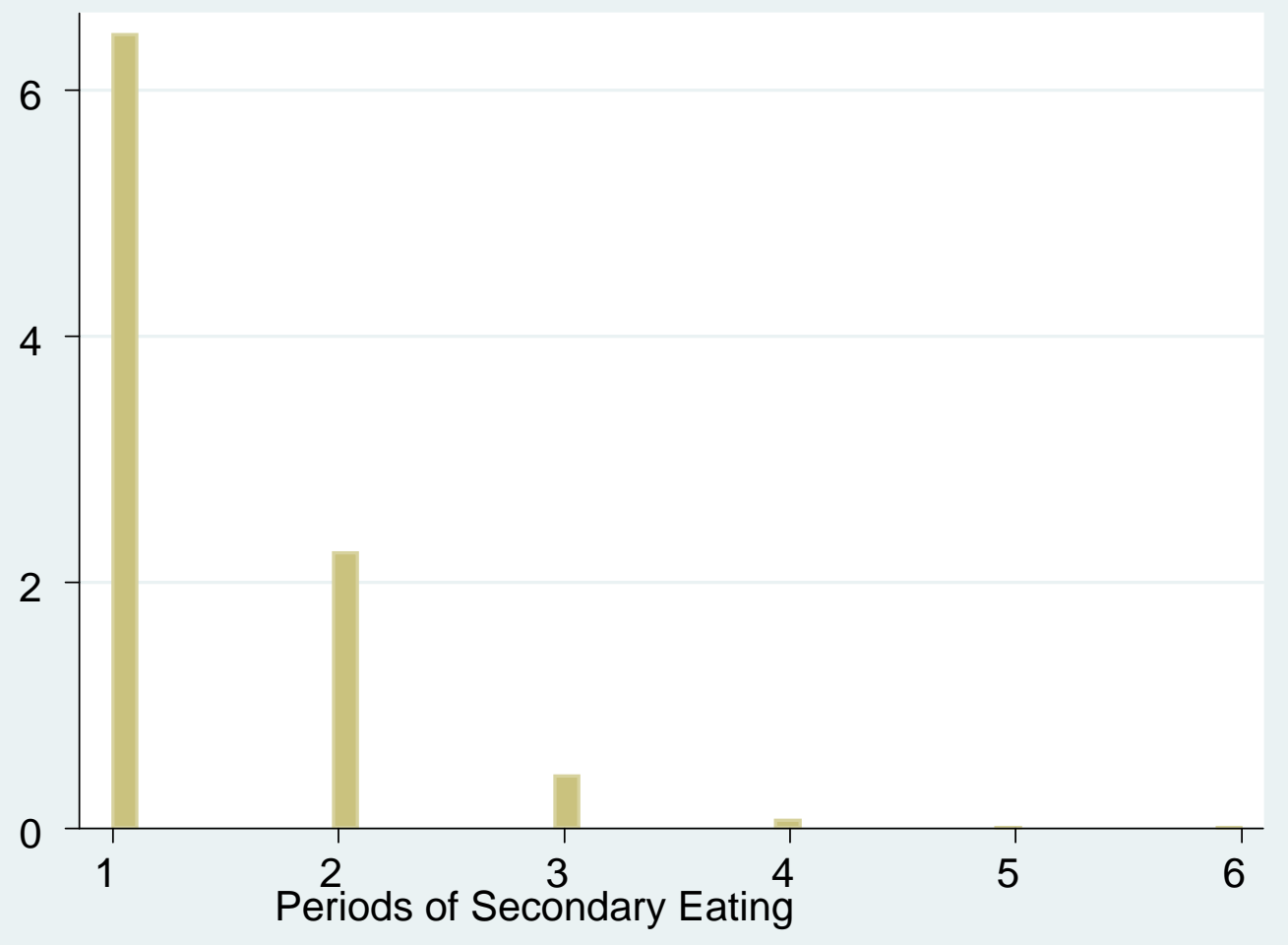

Figure 2c. Histogram of Intervals of Secondary Eating (Excluding the 1 Person with More than 6 Intervals) 


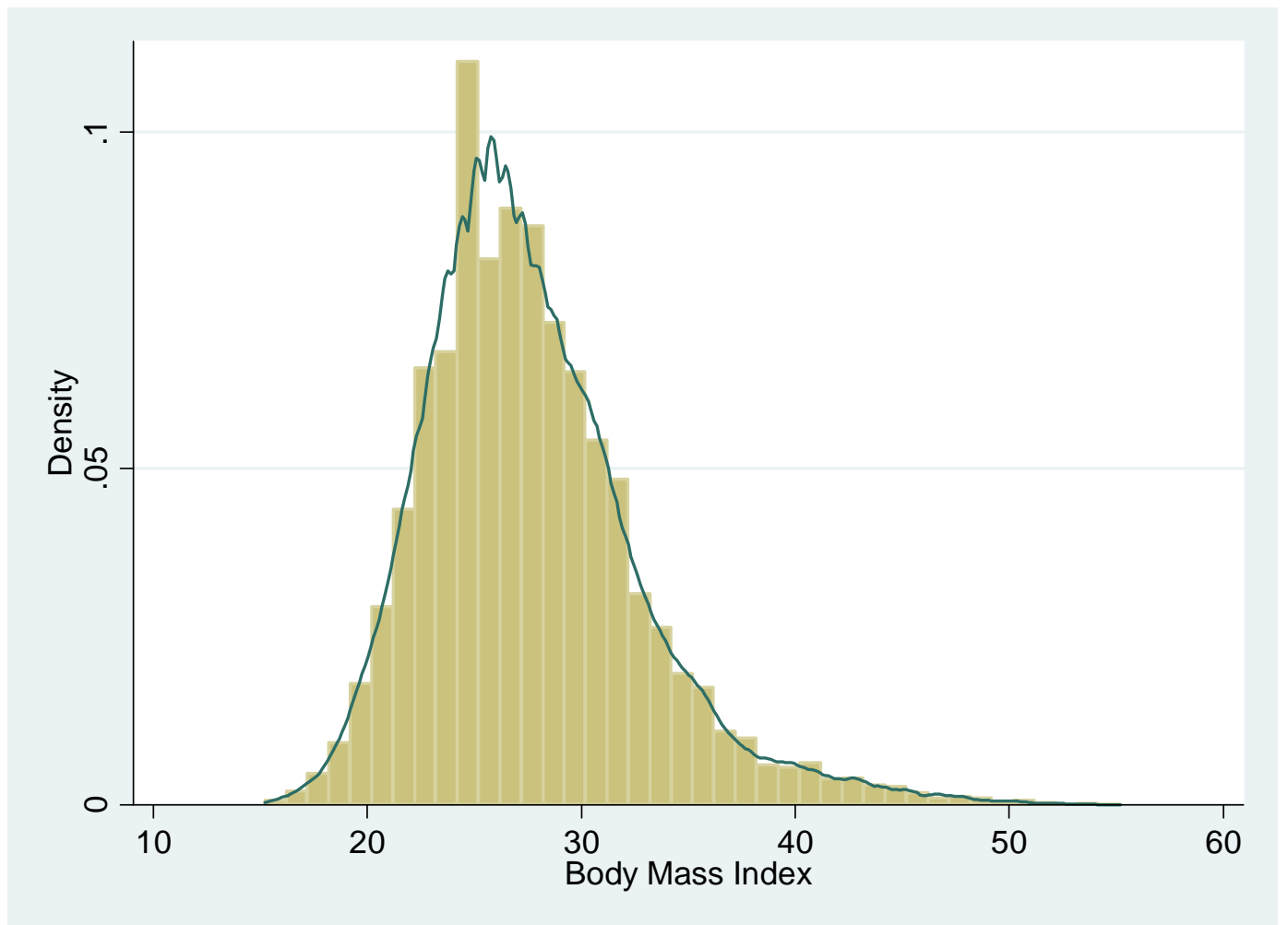

Figure 3a. Histogram and Kernel Density of BMI, Men (Excludes $0.05 \%$ with BMI $<15$ or $<55$ ) 


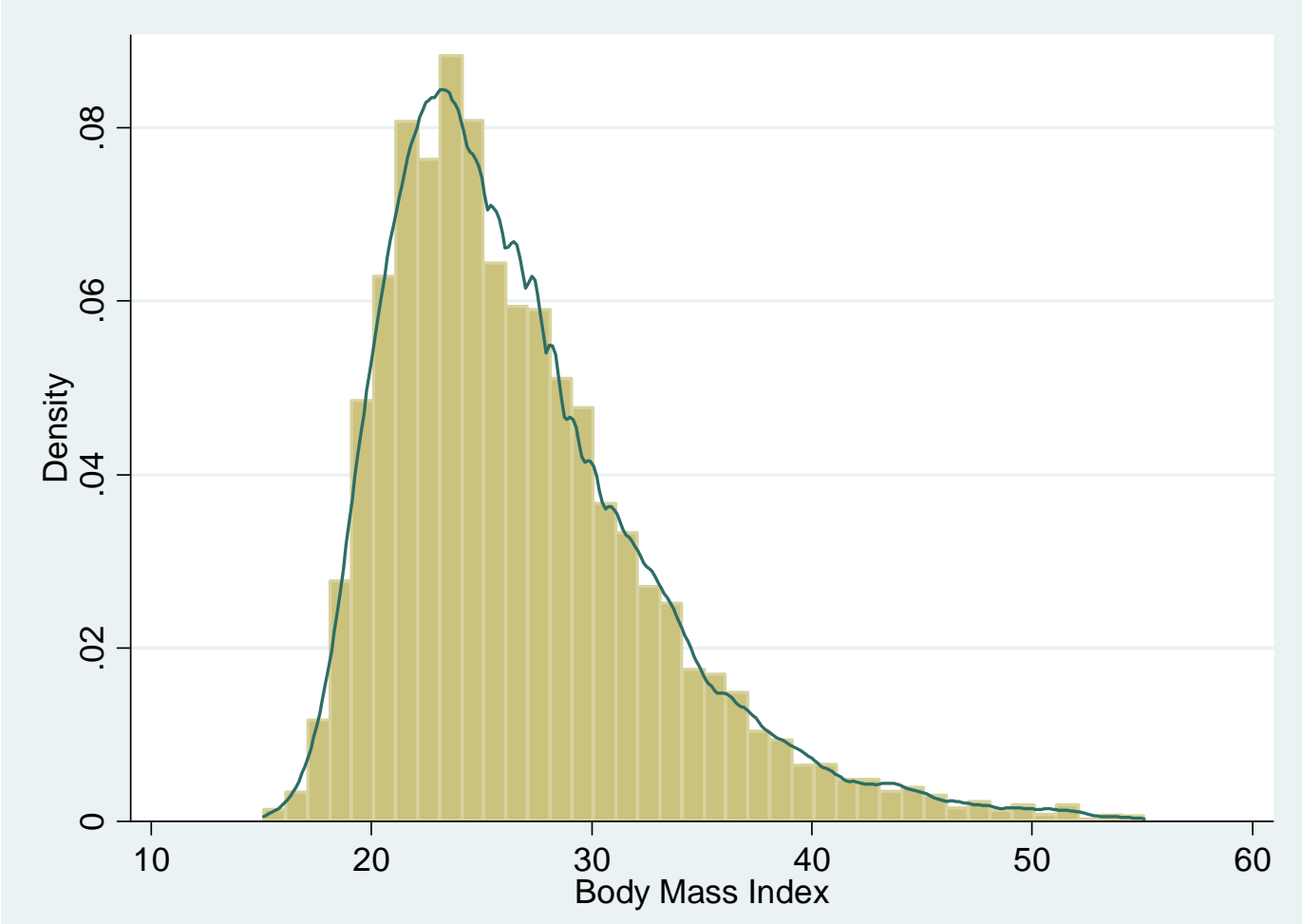

Figure 3b. Histogram and Kernel Density of BMI, Women (Excludes $0.2 \%$ with BMI $<15$ or $<55$ ) 
Table 1. Distributions of Eating/Drinking and Other Variables, Workers and Non-Workers, ATUS 2006-07*

\begin{tabular}{|c|c|c|c|c|c|}
\hline Variable & Workers & Non-Workers & Variable & Workers & Non-Workers \\
\hline $\mathrm{T}^{\mathrm{P}}$ & $\begin{array}{l}71.90 \\
(0.51)\end{array}$ & $\begin{array}{l}76.63 \\
(0.57)\end{array}$ & Age & $\begin{array}{l}39.94 \\
(0.12)\end{array}$ & $\begin{array}{l}48.90 \\
(0.20)\end{array}$ \\
\hline$n^{\mathrm{P}}$ & $\begin{array}{r}1.89 \\
(0.009)\end{array}$ & $\begin{array}{r}1.95 \\
(0.009)\end{array}$ & Male & $\begin{array}{r}0.53 \\
(0.004)\end{array}$ & $\begin{array}{c}0.43 \\
(0.005)\end{array}$ \\
\hline $\mathrm{T}^{\mathrm{S}}$ & $\begin{array}{l}77.57 \\
(1.62)\end{array}$ & $\begin{array}{l}59.62 \\
(1.52)\end{array}$ & White & $\begin{array}{r}0.83 \\
(0.003)\end{array}$ & $\begin{array}{c}0.82 \\
(0.003)\end{array}$ \\
\hline $\mathrm{n}^{\mathrm{S}}$ & $\begin{array}{r}1.03 \\
(0.010)\end{array}$ & $\begin{array}{r}0.88 \\
(0.01)\end{array}$ & Hispanic & $\begin{array}{r}0.14 \\
(0.003)\end{array}$ & $\begin{array}{l}0.13 \\
(0.003)\end{array}$ \\
\hline $\mathrm{T}^{\mathrm{S}}$ (eat) & $\begin{array}{l}22.68 \\
(0.75)\end{array}$ & $\begin{array}{l}19.29 \\
(0.72)\end{array}$ & Married & $\begin{array}{r}0.57 \\
(0.004)\end{array}$ & $\begin{array}{c}0.52 \\
(0.005)\end{array}$ \\
\hline $\mathrm{n}^{\mathrm{S}}$ (eat) & $\begin{array}{r}0.76 \\
(0.007)\end{array}$ & $\begin{array}{r}0.66 \\
(0.007)\end{array}$ & $\mathrm{EDUC}=12$ & $\begin{array}{r}0.29 \\
(0.004)\end{array}$ & $\begin{array}{l}0.31 \\
(0.004)\end{array}$ \\
\hline & & & EDUC1315 & 0.28 & 0.22 \\
\hline $\begin{array}{l}\text { Weekly } \\
\text { Earnings }\end{array}$ & $\begin{array}{r}824.18 \\
(6.30)\end{array}$ & & & $(0.004)$ & $(0.003)$ \\
\hline $7 \mathrm{~T}^{\mathrm{H}}$ & $\begin{array}{l}41.14 \\
(0.11)\end{array}$ & & EDUC16 & $\begin{array}{r}0.20 \\
(0.003)\end{array}$ & $\begin{array}{c}0.12 \\
(0.003)\end{array}$ \\
\hline & & & EDUC 16+ & $\begin{array}{r}0.11 \\
(0.003)\end{array}$ & $\begin{array}{c}0.07 \\
(0.002)\end{array}$ \\
\hline & & & $\begin{array}{l}\text { No. } \\
\text { Children }\end{array}$ & $\begin{array}{r}0.61 \\
(0.009)\end{array}$ & $\begin{array}{c}0.34 \\
(0.009)\end{array}$ \\
\hline $\mathrm{N}=$ & 13,268 & 11,856 & & & \\
\hline
\end{tabular}

*Standard errors of means in parentheses. All statistics here and in the following tables are weighted by the ATUS Eating and Health module sampling weights, so that the results are for a representative individual and day of the week. 
Table 2. Estimates of the Determinants of Primary and Secondary Eating/Drinking Time and Incidence, $\mathrm{N}=\mathbf{2 5 , 1 2 4 *}$

\begin{tabular}{|c|c|c|c|c|c|c|}
\hline & I & oi & Estimation & Method & Tohit & Poisso \\
\hline 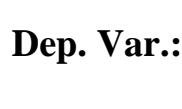 & ${ }^{\mathbf{T}^{\mathbf{P}}}$ & $\begin{array}{l}\mathbf{n}^{\mathbf{P}} \\
(2)\end{array}$ & $\begin{array}{l}\mathbf{T}^{S} \\
(3)\end{array}$ & $\begin{array}{l}\mathbf{n}^{\mathbf{s}} \\
(4)\end{array}$ & $\mathbf{T}_{(5)}^{\text {SFOOD }}$ & $\begin{array}{c}\mathbf{n}^{\text {SFOOD }} \\
(6)\end{array}$ \\
\hline
\end{tabular}

Ind. Var.:

Age

$\begin{array}{llcccc}-1.14 & -0.0071 & 1.506 & 0.0042 & -0.733 & -0.0044 \\ (0.12) & (0.0014) & (0.601) & (0.0035) & (0.283) & (0.0034)\end{array}$

Age2

$\begin{array}{rrrrrr}0.0150 & 0.00011 & -0.042 & -0.00014 & -0.0037 & -0.00005 \\ (0.0013) & (0.00001) & (0.006) & (0.00004) & (0.003) & (0.00004)\end{array}$

Male

$\begin{array}{rccccc}3.53 & 0.0292 & -16.922 & -0.2081 & -4.340 & -0.2101 \\ (0.75) & (0.0086) & (3.665) & (0.0202) & (1.727) & (0.0198)\end{array}$

White

$\begin{array}{lccccc}13.24 & 0.1336 & 50.595 & 0.2623 & 8.031 & 0.1573 \\ (1.01) & (0.0130) & (4.982) & (0.0274) & (2.333) & (0.0269)\end{array}$

Hispanic

$0.66 \quad 0.0433 \quad-104.50$

$-0.4985$

$-36.970$

$-0.3928$

$(1.18)$

$(6.034)$

(0.0370)

(2.833)

(0.0392)

Married

$6.81 \quad 0.0882$

24.759

$-0.0083$

$\begin{array}{ll}11.292 & 0.0099\end{array}$

(0.91) (0.0101)

(4.434)

(0.0228)

(2.092)

(0.0231)

$\mathrm{EDUC}=12$

$\begin{array}{ll}7.02 & -0.0043\end{array}$

55.218

0.1307

20.275

0.0891

(1.19) (0.0144)

(6.017)

(0.0388)

(2.835)

(0.0374)

EDUC1315

$14.68 \quad 0.0426$

52.434

0.2328

17.937

0.2047

(1.24) (0.0150)

(6.162)

(0.0376)

(2.902)

(0.0367)

EDUC 16

$$
20.57 \quad 0.0986
$$

56.568

0.3809

22.440

0.3581

(1.38) (0.0158)

(6.835)

(0.0394)

(3.218)

(0.0378)

EDUC 16+

$\begin{array}{ll}24.58 & 0.1027 \\ (1.65) & (0.0176)\end{array}$

78.723

0.4667

31.747

0.4359

(8.018)

(0.0434)

(3.772)

(0.0406)

No. Children

$\begin{array}{llllll}-1.22 & -0.0022 & -19.181 & 0.0078 & -7.312 & -0.0019 \\ (0.41) & (0.006) & (2.032) & (0.010) & (0.956) & (0.0093)\end{array}$

Adjusted $\mathrm{R}^{2}, \mathrm{X}^{2}$ or pseudo- $\mathrm{R}^{2}$ 
Table 3. Estimates of the Effects of the Price of Time on Primary and Secondary Eating/Drinking Time and Incidence, $\mathrm{N}=12,825$ Workers*

\begin{tabular}{|c|c|}
\hline Controls & $\begin{array}{l}\text { Demographic } \\
\text { Controls Only }\end{array}$ \\
\hline
\end{tabular}

Dep. Var.

$\begin{array}{lccc}\mathbf{T}^{\mathbf{P}} & 0.1955 & 0.3481 & 0.3974 \\ & (0.0438) & (0.0400) & (0.0378) \\ \mathbf{n}^{\mathbf{P}} & & & \\ & -0.00023 & 0.0007 & 0.0019 \\ & (0.00047) & (0.0004) & (0.0004) \\ \mathbf{T}^{\mathbf{S}} & & & \\ & 0.5740 & 0.8341 & 0.8698 \\ & (0.2148) & (0.1956) & (0.1854) \\ \mathbf{n}^{\mathbf{S}} & & & \\ & 0.0028 & 0.0060 & 0.0060 \\ & (0.0009) & (0.0008) & (0.0008) \\ \mathbf{T}^{\mathbf{S}} \text { (eating only) } & & & \\ & 0.1587 & 0.3168 & 0.2202 \\ & (0.0990) & (0.0909) & (0.0858) \\ \mathbf{n}^{\text {S }} \text { (eating only) } & & & \\ & 0.0033 & 0.0064 & 0.0056 \\ & (0.0009) & (0.0008) & (0.0008)\end{array}$

*Includes all observations with computed hourly earnings $\geq \$ 5.15$ and $\leq \$ 100$. 
Table 4. BMI in the ATUS 2006-07 and the NHANES 2003-2006*

\begin{tabular}{lcccc} 
Percentile & \multicolumn{2}{c}{ Men 20+ } & \multicolumn{2}{c}{ Women 20+ } \\
& ATUS & NHANES & ATUS & NHANES \\
& & & & \\
5 & 21.4 & 20.8 & 19.5 & 19.4 \\
10 & 22.5 & 22.1 & 20.5 & 20.7 \\
25 & 24.4 & 24.6 & 22.6 & 23.1 \\
50 & 27.2 & 27.7 & 25.7 & 26.9 \\
75 & 30.5 & 31.2 & 30.1 & 32.2 \\
90 & 34.3 & 35.3 & 35.3 & 38.1 \\
95 & 37.3 & 38.6 & 39.1 & 41.6 \\
& & & & \\
Mean & 28.0 & 28.4 & 26.9 & 28.4
\end{tabular}

*NHANES data are from NCHS (2008), Tables 14 and 15. 
Table 5. Percent Distributions of Subjective Health Status by Gender, ATUS Eating and Health Module, 2006-07

\section{Men Women}

Health Status:

$\begin{array}{lrr}\text { Excellent } & 19.1 & 18.1 \\ \text { Very Good } & 34.0 & 34.0 \\ \text { Good } & 29.9 & 30.1 \\ \text { Fair } & 12.6 & 13.1 \\ \text { Poor } & 4.4 & 4.7 \\ & & \\ \mathrm{~N}= & 10,674 & 14,157\end{array}$

Chi-square(4) 29.95 
Table 6. OLS Estimates of the Determinants of BMI, N=23,691*

\section{Ind. Var.:}

\begin{tabular}{|c|c|c|c|c|c|c|c|c|}
\hline \multirow[t]{3}{*}{$\begin{array}{l}\text { Ind. Var.: } \\
\text { Age }\end{array}$} & $\begin{array}{c}(1) \\
0.3521\end{array}$ & & (2) & (3) & (4) & (5) & (6) & (7) \\
\hline & $(0.0116)$ & $\mathrm{T}^{\mathrm{P}}$ & -0.00174 & -0.00003 & -0.00167 & -0.00002 & -0.00186 & -0.00007 \\
\hline & & & $(0.00060)$ & $(0.00069)$ & $(0.00060)$ & $(0.00069)$ & $(0.00060)$ & $(0.00069)$ \\
\hline \multirow[t]{3}{*}{ Age2 } & -0.00326 & & & & & & & \\
\hline & $(0.00012)$ & $\mathrm{n}^{\mathrm{P}}$ & & -0.2224 & & -0.2270 & & -0.2466 \\
\hline & & & & $(0.0438)$ & & $(0.0445)$ & & $(0.0447)$ \\
\hline \multirow[t]{3}{*}{ Male } & 1.0526 & & & & & & & \\
\hline & $(0.0720)$ & $\mathrm{T}^{\mathrm{s}}$ & & & 0.00019 & 0.00015 & & \\
\hline & & & & & $(0.00020)$ & $(0.00022)$ & & \\
\hline \multirow[t]{3}{*}{ White } & -1.0154 & & & & & & & \\
\hline & $(0.0964)$ & $\mathrm{n}^{\mathrm{s}}$ & & & & -0.04110 & & \\
\hline & & & & & & $(0.03515)$ & & \\
\hline \multirow[t]{3}{*}{ Hispanic } & 0.9015 & & & & & & & \\
\hline & $(0.1142)$ & $\mathrm{T}^{\mathrm{S}}$ & ating only) & & & & -0.00140 & -0.00144 \\
\hline & & & & & & & $(0.00043)$ & $(0.00045)$ \\
\hline \multirow[t]{3}{*}{ Married } & -0.1277 & & & & & & & \\
\hline & $(0.0868)$ & $\mathrm{n}^{\mathrm{S}}($ & ting only) & & & & & -0.0674 \\
\hline & & & & & & & & $(0.0487)$ \\
\hline \multirow[t]{2}{*}{$\mathrm{EDUC}=12$} & 0.4011 & & & & & & & \\
\hline & $(0.1142)$ & & & & & & & \\
\hline \multirow[t]{2}{*}{ EDUC1315 } & 0.1460 & & & & & & & \\
\hline & $(0.1184)$ & & & & & & & \\
\hline \multirow[t]{2}{*}{ EDUC 16} & -1.3575 & & & & & & & \\
\hline & $(0.1324)$ & & & & & & & \\
\hline \multirow[t]{2}{*}{ EDUC 16+ } & -1.7265 & & & & & & & \\
\hline & $(0.1570)$ & & & & & & & \\
\hline
\end{tabular}

No. Children $\quad 0.0871$

(0.0399)

Adjusted $\mathrm{R}^{2}$

$\begin{array}{lrrrrrr}0.0818 & 0.0821 & 0.0830 & 0.0821 & 0.0830 & 0.0824 & 0.0836\end{array}$

*The equations shown in Columns (2)-(7) include all the controls that make up the estimates in Column (1). 
Table 7. Quantile Estimates of the Determinants of BMI, N=23,691*

\begin{tabular}{|c|c|c|c|c|c|c|}
\hline & $\mathrm{T}^{\mathrm{P}}$ & $n^{P}$ & $\begin{array}{l}\text { Dep. } \\
T^{S}\end{array}$ & $\begin{array}{l}\text { Var. } \\
\qquad \mathrm{n}^{\mathrm{S}}\end{array}$ & $\mathrm{T}^{\mathrm{S}}$ (eating only) & $\mathrm{n}^{\mathrm{S}}$ (eating only) \\
\hline \multicolumn{7}{|c|}{ Quantile } \\
\hline \multirow[t]{10}{*}{95 th } & -0.00191 & & & & & \\
\hline & $(0.00360)$ & & & & & \\
\hline & -0.00025 & -0.2626 & & & & \\
\hline & $(0.00425)$ & $(0.1950)$ & & & & \\
\hline & -0.00140 & & -0.00060 & & & \\
\hline & $(0.00359)$ & & $(0.00091)$ & & & \\
\hline & -0.00036 & -0.2649 & -0.00042 & -0.0637 & & \\
\hline & $(0.00433)$ & $(0.2002)$ & $(0.00108)$ & $(0.1768)$ & & \\
\hline & -0.00007 & -0.2970 & & & -0.00221 & -0.1287 \\
\hline & $(0.00404)$ & $(0.1889)$ & & & $(0.00171)$ & $(0.2319)$ \\
\hline \multirow[t]{9}{*}{ 90th } & $\begin{array}{l}-0.00240 \\
(0.00203)\end{array}$ & & & & & \\
\hline & 0.00037 & -0.3390 & & & & \\
\hline & $(0.00245)$ & $(0.1367)$ & & & & \\
\hline & -0.00228 & & 0.00078 & & & \\
\hline & $(0.00202)$ & & $(0.00202)$ & & & \\
\hline & 0.00045 & -0.36431 & 0.00064 & -0.0756 & & \\
\hline & $(0.00232)$ & $(0.1346)$ & $(0.00070)$ & $(0.1195)$ & & \\
\hline & 0.00027 & -0.41219 & & & -0.00104 & -0.1275 \\
\hline & $(0.00204)$ & $(0.1170)$ & & & $(0.00161)$ & $(0.1344)$ \\
\hline
\end{tabular}


Table 8. Ordered Probit Estimates of the Determinants of Subjective Health, $N=\mathbf{2 4 , 8 3 1 *}$

Ind. Var.:

Ind. Var.:

(1)

$-0.0231$

(2)

(3)

(4)

(5)

(6)

(7)

Age

(0.0022)

$\mathrm{T}^{\mathrm{P}} \quad 0.00078$

0.00039

0.00074

0.00043

0.00079

0.00045

(0.00011)

(0.00013)

(0.00011)

(0.00013)

$(0.00011) \quad(0.00013)$

Age2

$0.00007 \quad \mathrm{n}^{\mathrm{P}}$

0.04861

0.0513

0.0592

(0.00002)

(0.00831)

(0.0084)

(0.0085)

Male

$\begin{array}{rr}0.0299 & \mathrm{~T}^{\mathrm{S}} \\ (0.0135) & \end{array}$

$-0.00012-0.00015$

$(0.00004) \quad(0.00004)$

White

$0.2483 \quad \mathrm{n}^{\mathrm{S}}$

0.03239

(0.00665)

(0.0182)

$\mathrm{T}^{\mathrm{S}}$

Hispanic

$-0.3131 \quad$ (eating only)

$0.00013 \quad 0.00004$

$(0.0211)$

$(0.00008) \quad(0.00008)$

Married

0.1417

$\mathrm{n}^{\mathrm{S}}$

(0.0163)

(eating only)

0.0558

(0.0092)

EDUC $=12 \quad 0.1931$

(0.0211)

EDUC1315 $\quad 0.4367$

(0.0222)

EDUC $16 \quad 0.7426$

(0.0251)

EDUC 16+ $\quad 0.9389$

(0.0301)

No.

Children $\quad-0.0180$

(0.0074)

Pseudo-R ${ }^{2} \quad 0.0517$

0.0523

0.0528

0.0525

0.0532

0.0524

0.0534

*Columns (2)-(7) also include all the controls that make up the estimates in Column (1). 
Table 9. Descriptive Statistics, Unmarried Childless Respondents, $N=2,262$, and Expanded Sub-sample, $N=4,582^{*}$

\begin{tabular}{|c|c|c|c|c|c|}
\hline & Sul & -sample & & Sub- & -sample \\
\hline & Restricted & Expanded & & Restricted & Expanded \\
\hline Variable & & & & & \\
\hline Food Last & 92.85 & 89.85 & Age & 51.96 & 50.10 \\
\hline Week (\$) & $(1.52)$ & $(0.94)$ & & $(0.40)$ & $(0.25)$ \\
\hline Usual Weekly Food & 81.24 & 78.55 & Male & 0.44 & 0.43 \\
\hline Expenditures (\$) & $(1.25)$ & $(0.78)$ & & $(0.01)$ & $(0.01)$ \\
\hline $\mathbf{T}^{\mathbf{P}}$ & 76.04 & 76.14 & White & 0.79 & 0.84 \\
\hline & $(1.34)$ & $(0.89)$ & & $(0.01)$ & $(0.01)$ \\
\hline $\mathbf{n}^{\mathbf{P}}$ & 1.89 & 1.96 & Hispanic & 0.07 & 0.09 \\
\hline & $(0.02)$ & $(0.01)$ & & $(0.01)$ & $(0.004)$ \\
\hline $\mathbf{T}^{\mathrm{S}}$ & 62.79 & 68.46 & EDUC $=12$ & 0.32 & 0.32 \\
\hline & $(3.42)$ & $(2.56)$ & & $(0.01)$ & $(0.01)$ \\
\hline$n^{s}$ & 0.92 & 0.96 & EDUC1315 & 0.27 & 0.27 \\
\hline & $(0.02)$ & $(0.02)$ & & $(0.01)$ & $(0.01)$ \\
\hline $\mathbf{T}^{\mathrm{S}}$ (eating only) & 21.06 & 17.78 & EDUC 16 & 0.17 & 0.18 \\
\hline & $(1.61)$ & $(0.93)$ & & $(0.01)$ & $(0.01)$ \\
\hline $\mathrm{n}^{\mathrm{s}}$ (eating only) & 0.72 & 0.72 & EDUC 16+ & 0.11 & 0.12 \\
\hline & $(0.02)$ & $(0.01)$ & & $(0.01)$ & $(0.01)$ \\
\hline Fraction & 0.48 & 0.53 & & & \\
\hline Working & $(0.01)$ & $(0.01)$ & & & \\
\hline
\end{tabular}


Table 10. Estimates of the Relationship between Eating Time and Food Spending, Restricted Sub-sample of Unmarried Childless Respondents, $\mathrm{N}=2,262$, and Expanded Subsample, $N=4,582^{*}$

\section{Last Week’s Spending}

Sub-sample: Restricted

(1) (2)

\section{Expanded}

(3) (4)

\section{Usual Weekly Spending}

Restricted

(5) (6)

\section{Expanded}

(7)

(8)

Time

Input:

$\begin{array}{lcccccccc}\mathbf{T}^{\mathbf{P}} & 0.0631 & 0.0618 & 0.1191 & 0.1201 & 0.0458 & 0.0461 & 0.0920 & 0.0938 \\ & (0.0276) & (0.0275) & (0.0178) & (0.0178) & (0.0230) & (0.0230) & (0.0148) & (0.0148) \\ \mathbf{n}^{\mathbf{P}} & & & & & & & & \\ & -6.599 & -6.668 & -5.825 & -5.546 & -3.293 & -3.026 & -3.802 & -3.454 \\ & (1.849) & (1.858) & (1.141) & (1.144) & (1.544) & (1.550) & (0.948) & (0.950) \\ \mathbf{T}^{\mathbf{S}} & & & & & & & & \\ & -0.0097 & & -0.0118 & & -0.0019 & & -0.0040 & \\ & (0.0097) & & (0.0057) & & (0.0081) & & (0.0047) & \\ \mathbf{n}^{\mathbf{S}} & & & & & & & 0.827 & \\ & 1.993 & & 1.372 & & 2.384 & & (0.732) & \end{array}$

$\mathbf{T}^{\mathrm{S}}$

(eating

only)

0.0075

0.0075

0.0172

0.0148

(0.0203)

(0.0153)

$(0.0170)$

(0.0127)

$n^{s}$
(eating
only)

Adjusted

$\begin{array}{lllllllll}\mathbf{R}^{2} & 0.0700 & 0.0691 & 0.0700 & 0.0687 & 0.0457 & 0.0471 & 0.0644 & 0.0653\end{array}$

*The estimates also include a quadratic in age, indicators of race, ethnicity and gender, and a vector of indicators for educational attainment, here and in Tables 11 and 12. 
Table 11. Estimates of the Effects of Goods and Time Inputs into Eating on BMI, Restricted Sub-sample of Unmarried Childless Respondents, $\mathrm{N}=2,187$, and Expanded Subsample, $N=4,351$

\section{Last Week’s Spending}

Sub-sample: Restricted

(1) (2)
Expanded

(3)

(4)
Usual Weekly Spending

Restricted

(5)

(6)
Expanded

(7)

(8)

Ind. Var.

$\begin{array}{lcccccccc}\mathbf{X}^{\mathbf{F}} & 0.0051 & 0.0052 & 0.0 .0029 & 0.0030 & 0.0034 & 0.0036 & 0.0022 & 0.0022 \\ & (0.0017) & (0.0017) & (0.0014) & (0.0014) & (0.0021) & (0.0021) & (0.0016) & (0.0016)\end{array}$

Time

Input:

$\begin{array}{lcccccccc}\mathbf{T}^{\mathbf{P}} & -0.0007 & -0.0009 & 0.0001 & 0.0002 & -0.0005 & -0.0007 & 0.0003 & 0.0004 \\ & (0.0023) & (0.0023) & (0.0016) & (0.0016) & (0.0023) & (0.0023) & (0.0016) & (0.0016) \\ \mathbf{n}^{\mathbf{P}} & & & & & & & & \\ & 0.0827 & 0.0674 & -0.2064 & -0.2026 & 0.0607 & 0.0439 & -0.2136 & -0.2095 \\ & (0.1528) & (0.0153) & (0.1049) & (0.1051) & (0.1527) & (0.1530) & (0.1049 & (0.1051) \\ \mathbf{T}^{\mathbf{S}} & & & & & & & & \\ & -0.0009 & & -0.0004 & & -0.0010 & & -0.0004 & \\ & (0.0008) & & (0.0005) & & (0.0008) & & (0.0005) & \\ \mathbf{n}^{\mathbf{S}} & & & & & & & & \\ & 0.2490 & & 0.0393 & & 0.2501 & & 0.0407 & \\ & (0.1220 & & (0.0815 & & (0.1222) & & (0.0815) & \end{array}$

$\mathbf{T}^{\mathrm{S}}$

(eating only)

$-0.0060$

$-0.0038$

$-0.0060$

$-0.0038$

(0.0017)

(0.0014)

(0.0017)

(0.0014)

$\mathbf{n}^{\mathrm{S}}$

(eating

only)

0.3123

0.1639

0.3038

0.1644

Adjusted

(0.1570)

(0.1128)

(0.1574)

(0.1128)

$\begin{array}{lllllllll}\mathbf{R}^{2} & 0.0515 & 0.0554 & 0.0568 & 0.0584 & 0.0489 & 0.0528 & 0.0562 & 0.0578\end{array}$


Table 12. Ordered Probit Estimates of the Effects of Goods and Time Inputs into Eating on Subjective Health, Restricted Sub-sample of Unmarried Childless Respondents, $\mathbf{N}=\mathbf{2 , 2 3 7}$, and Expanded Sub-sample, $N=4,538$

\section{Last Week’s Spending}

Sub-sample: Restricted

(1) (2)
Expanded

(3)

(4)
Restricted

(5)

\section{Usual Weekly Spending}

Expanded

(7)

Ind. Var.

$\begin{array}{ccccccccc}\mathbf{X}^{\mathbf{F}} & 0.0005 & 0.0006 & 0.0005 & 0.0005 & 0.0003 & 0.0003 & 0.0006 & 0.0006 \\ & (0.0003) & (0.0003) & (0.0003) & (0.0003) & (0.0004) & (0.0004) & (0.0003) & (0.0003)\end{array}$

Time

Input:

$\begin{array}{lcccccccc}\mathbf{T}^{\mathbf{P}} & 0.0004 & 0.0004 & 0.0006 & 0.0006 & 0.0004 & 0.0004 & 0.0006 & 0.0006 \\ & (0.0004) & (0.0004) & (0.0003) & (0.0003) & (0.0004) & (0.0004) & (0.0003) & (0.0003) \\ \mathbf{n}^{\mathbf{P}} & & & & & & & & \\ & -0.0006 & -0.0019 & 0.0194 & 0.0209 & -0.0030 & -0.0045 & 0.0189 & 0.0203 \\ & (0.0285) & (0.0286) & (0.0198) & (0.0199) & (0.0284) & (0.0286) & (0.0198) & (0.0199) \\ \mathbf{T}^{\mathbf{S}} & & & & & & & & \\ & -0.0003 & & -0.0003 & -0.0003 & & -0.0002 & \\ & (0.0001) & & (0.0002) & (0.0001) & & (0.0001) & \\ \mathbf{n}^{\mathbf{S}} & & & & & & & & \\ & 0.0387 & & 0.0383 & & 0.0391 & & 0.0385 & \\ & (0.0001) & & (0.0153) & (0.0227) & & (0.0153) & \end{array}$

$\mathbf{T}^{\mathrm{S}}$

(eating

only)

0.0002

$-0.0001$

0.0002

$-0.0001$

(0.00007)

(0.0003)

(0.0003)

(0.0003)

$\mathbf{n}^{\mathrm{S}}$

(eating

only)

$$
0.0015
$$

0.0339

0.0009

0.0335

Pseudo-

(0.0294)

(0.0211)

(0.0294)

(0.0211)

$\mathbf{R}^{2}$

0.0826

0.081

$\begin{array}{ll}0.0620 & 0.0617\end{array}$

0.0823

0.0814

0.0621

0.0617 